Supporting Information

\title{
Group 6 Carbonyl Complexes of C-Ylidic Cp Ligands
}

\author{
Fabio Mazzotta ${ }^{a}$, Karl W. Törnroos ${ }^{b}$, and Doris Kunz ${ }^{a *}$ \\ anstitut für Anorganische Chemie, Eberhard Karls Universität Tübingen, Auf der Morgenstelle 18, \\ 72076 Tübingen, Germany. ${ }^{b}$ Department of Chemistry, University of Bergen, Allégaten 41, 5007 \\ Bergen, Norway.
}

Table of contents

1. NMR spectra S2

2. IR spectra S16

3. Additional X-ray structure analyses $\quad$ S22

4. DFT S25 


\section{NMR spectra}

Spectra of complex 4
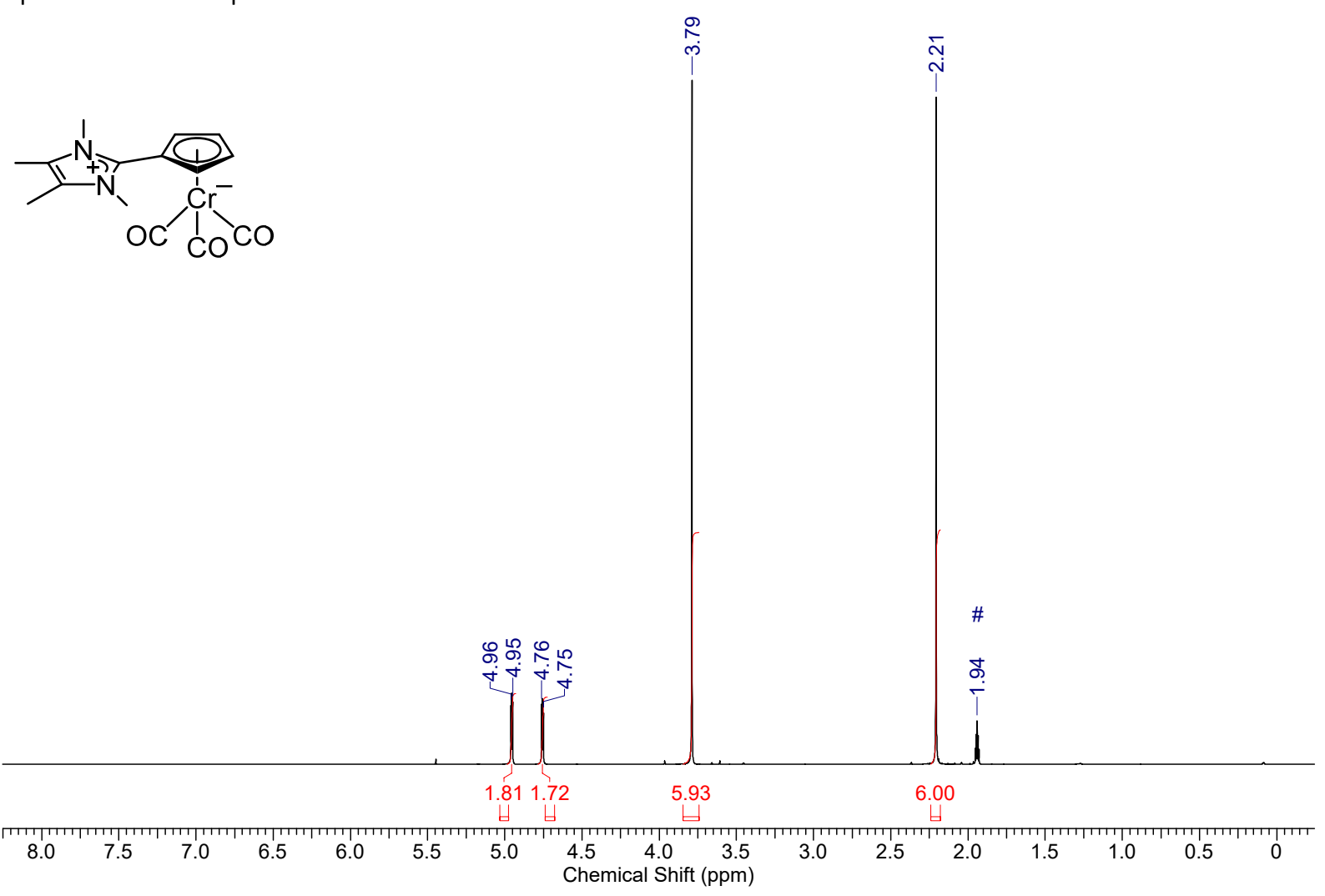

Figure S1. ${ }^{1} \mathrm{H}$ NMR spectrum ( $\left.400 \mathrm{MHz}, \mathrm{CD}_{3} \mathrm{CN} \#\right)$ of complex 4.

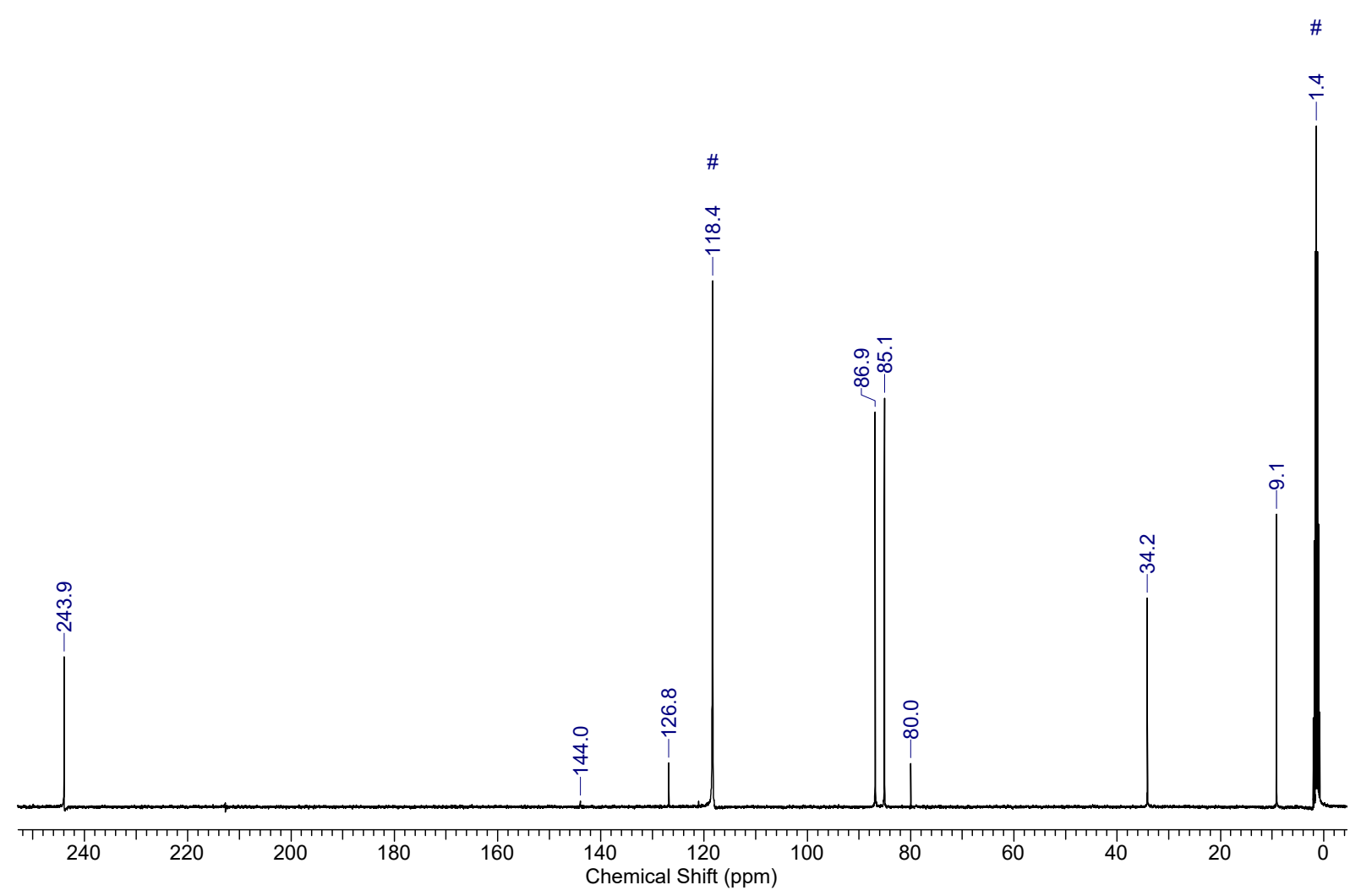

Figure S2. ${ }^{13} \mathrm{C}$ NMR spectrum $\left(101 \mathrm{MHz}, \mathrm{CD}_{3} \mathrm{CN} \#\right)$ of complex 4 . 


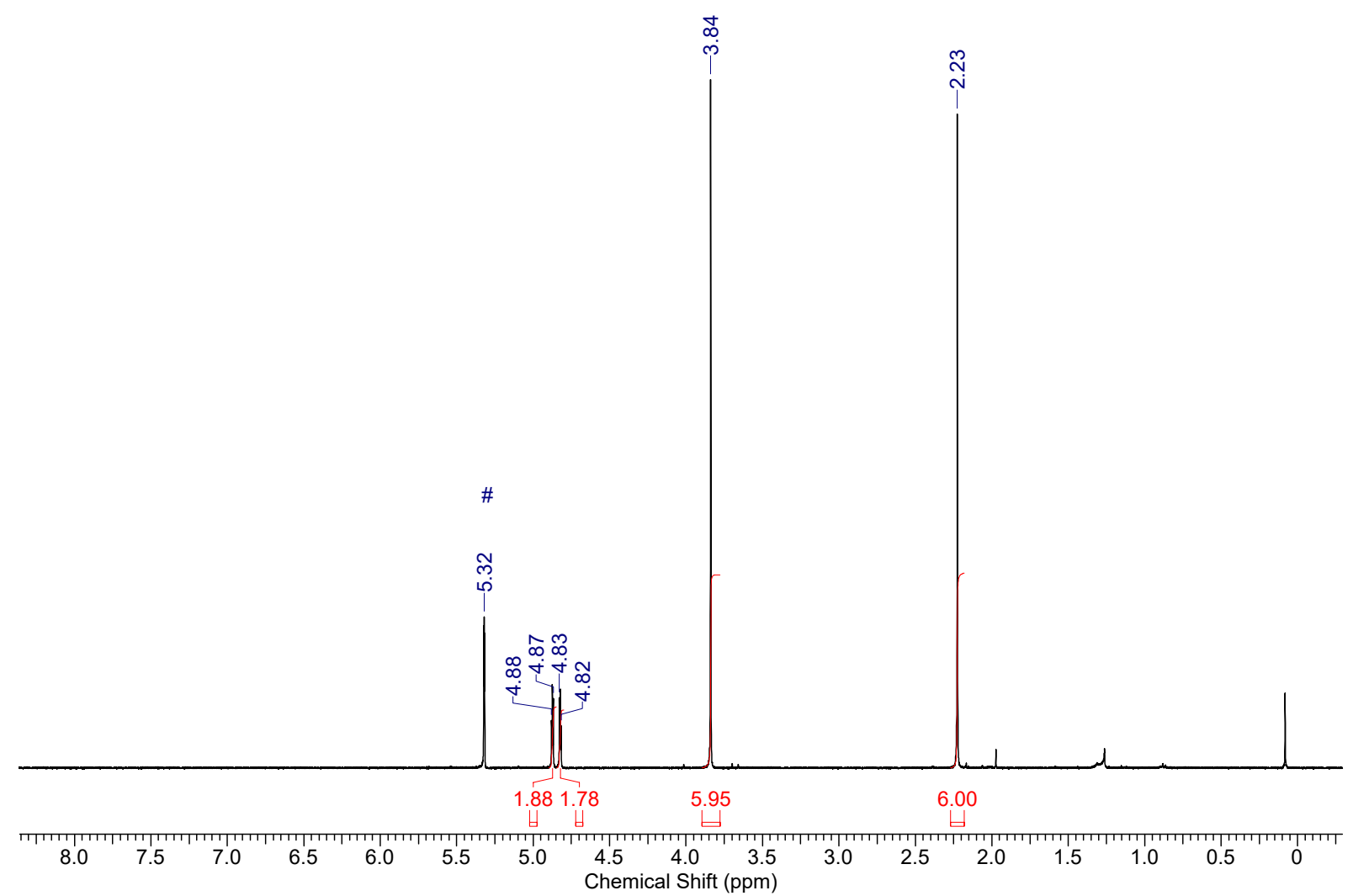

Figure S3. ${ }^{1} \mathrm{H}$ NMR spectrum $\left(400 \mathrm{MHz}, \mathrm{CD}_{2} \mathrm{Cl}_{2} \#\right)$ of complex 4 .

Spectra of complex 5
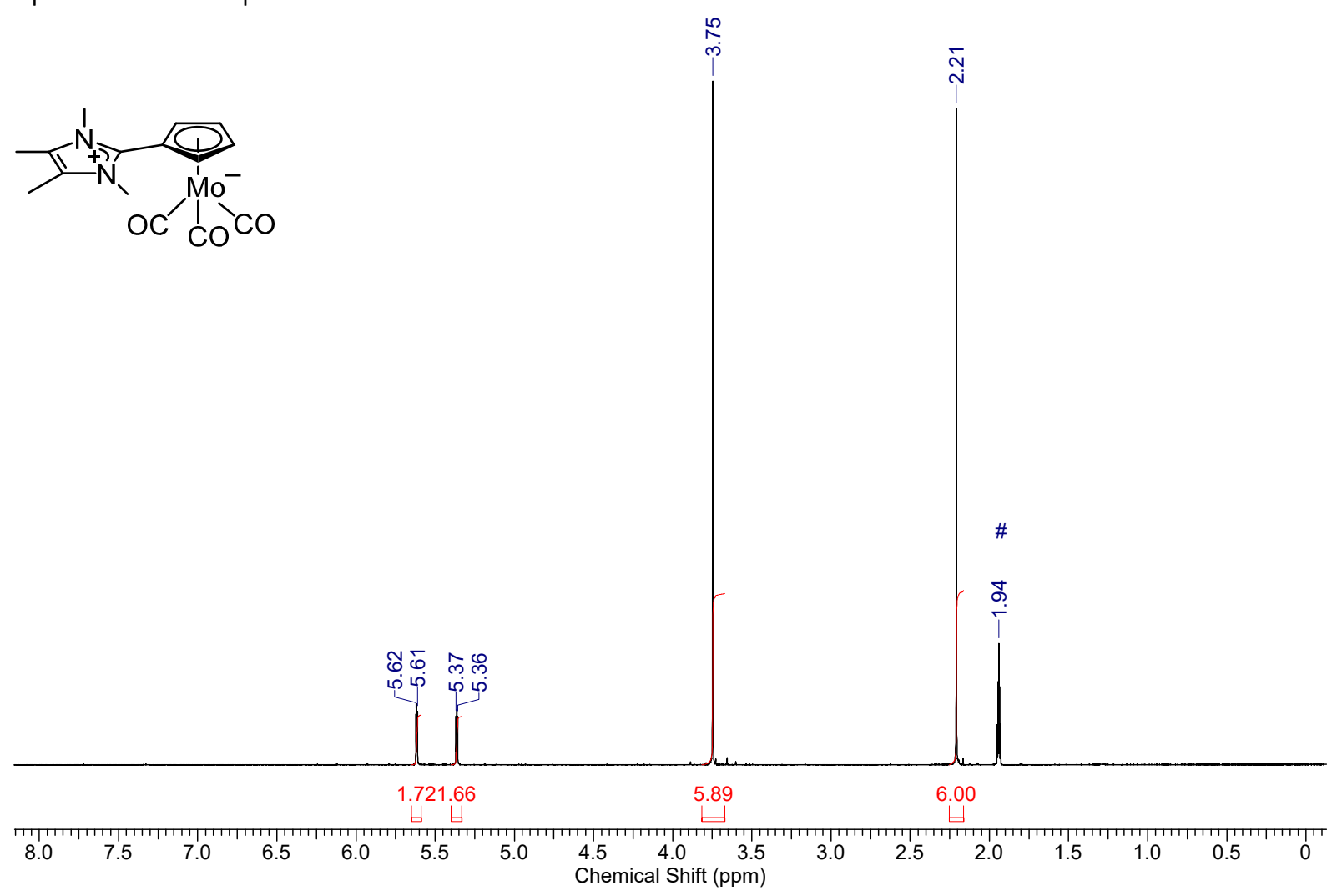

Figure S4. ${ }^{1} \mathrm{H}$ NMR spectrum $\left(500 \mathrm{MHz}, \mathrm{CD}_{3} \mathrm{CN} \#\right)$ of complex 5. 


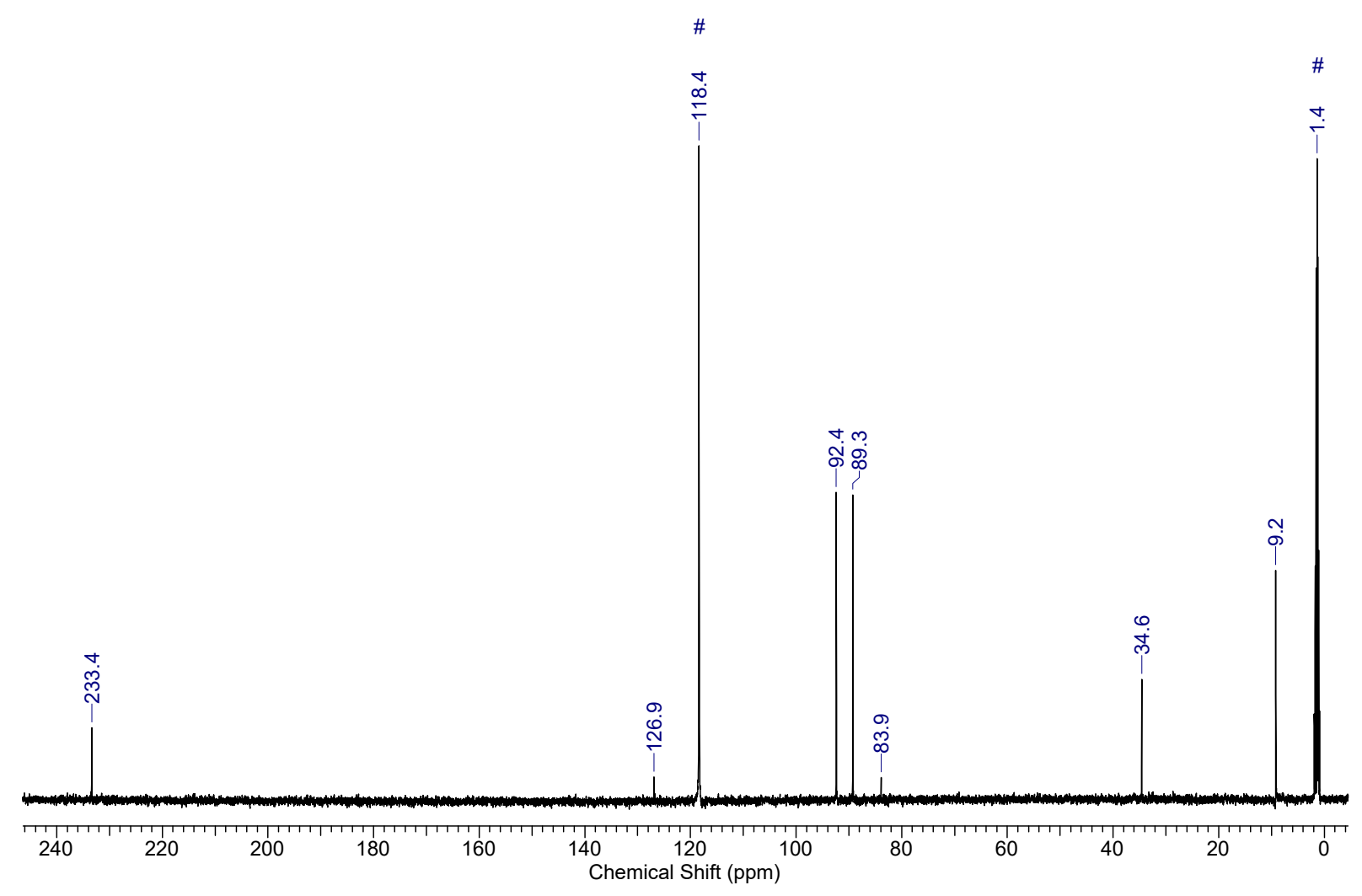

Figure S5. ${ }^{13} \mathrm{C}$ NMR spectrum (126 MH, $\left.\mathrm{CD}_{3} \mathrm{CN} \#\right)$ of complex 5.

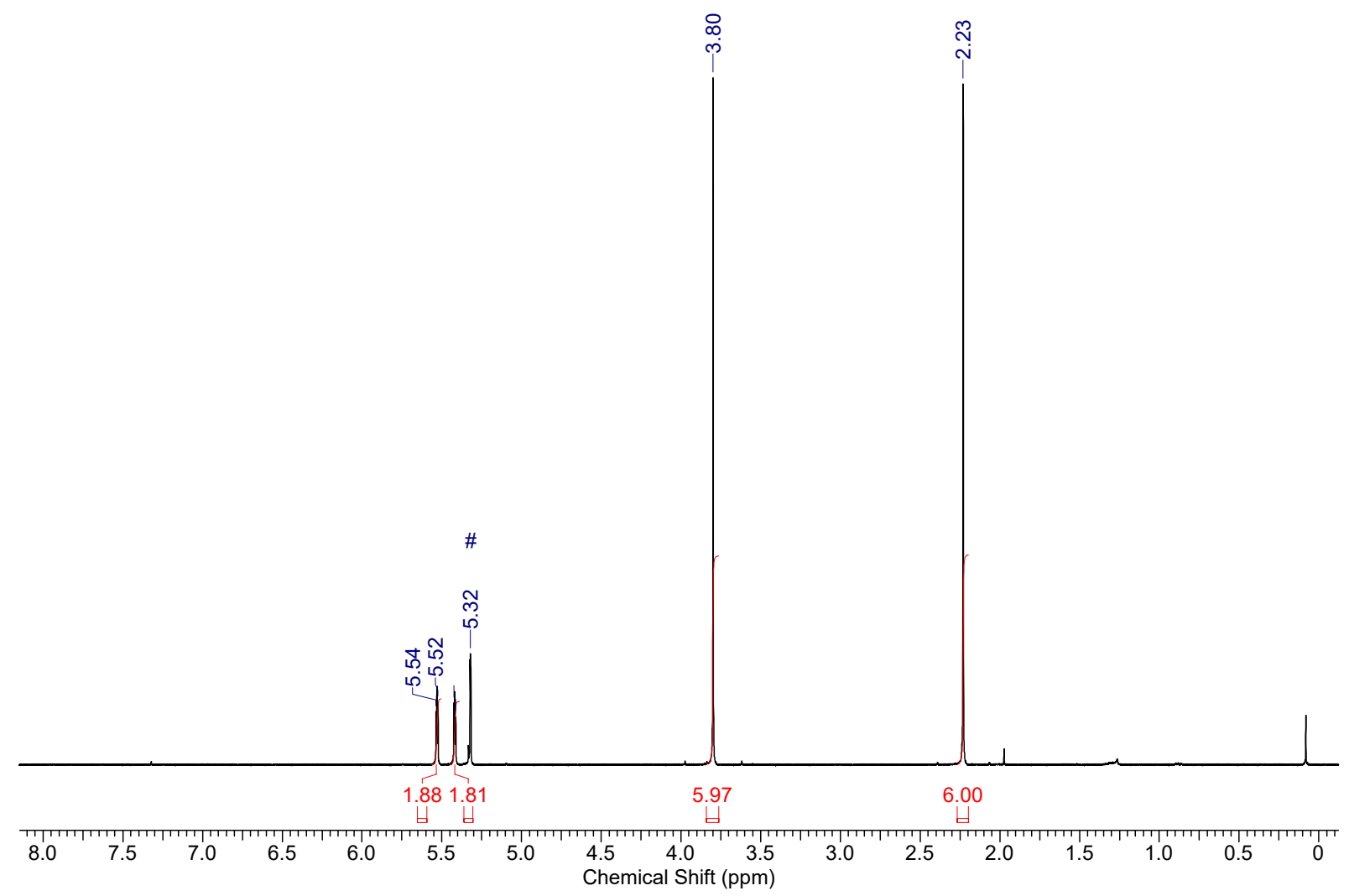

Figure S6. ${ }^{1} \mathrm{H}$ NMR spectrum $\left(400 \mathrm{MHz}, \mathrm{CD}_{2} \mathrm{Cl}_{2} \#\right)$ of complex 5 . 
Spectra of complex 6
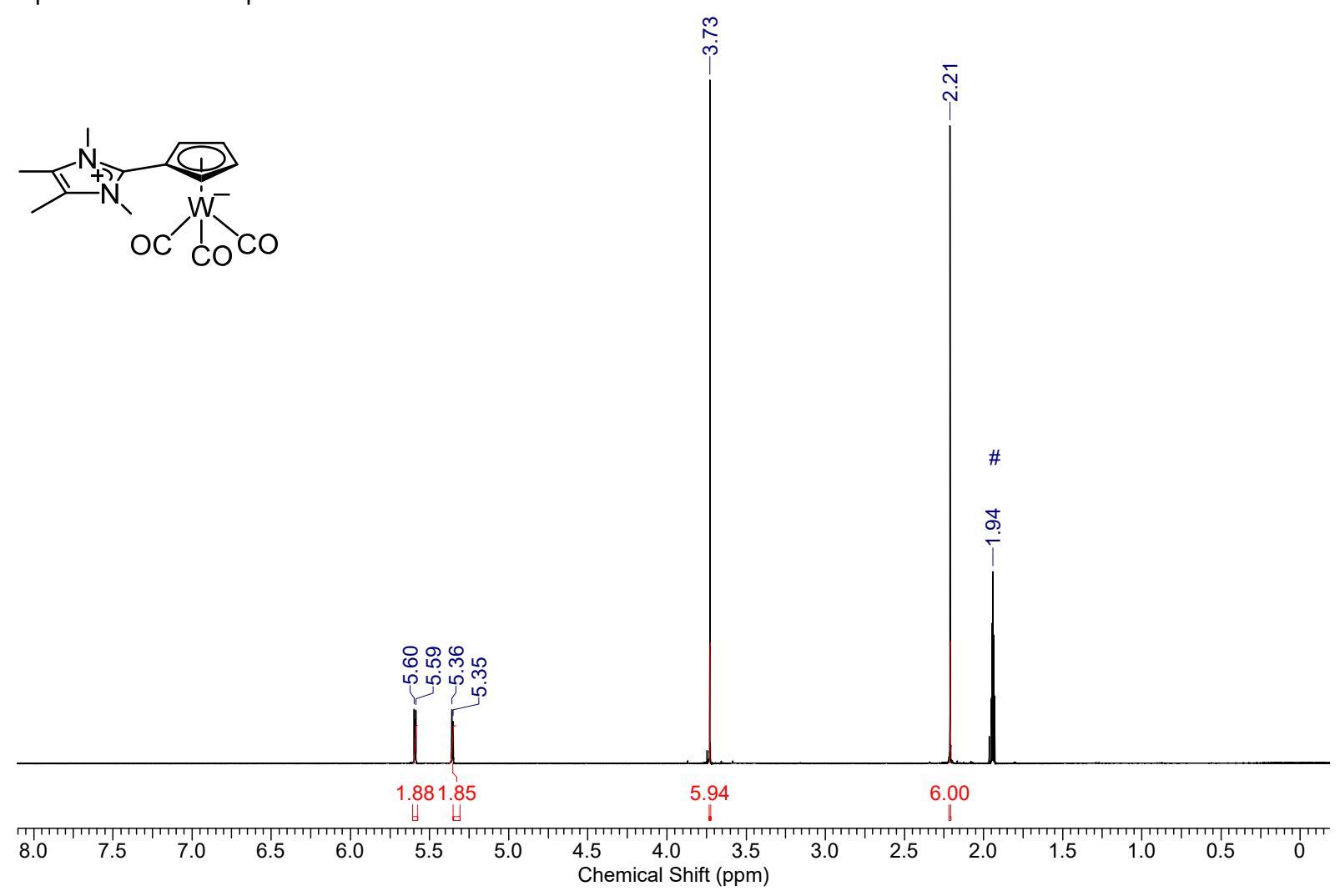

Figure S7. ${ }^{1} \mathrm{H}$ NMR spectrum $\left(500 \mathrm{MHz}, \mathrm{CD}_{3} \mathrm{CN} \#\right)$ of complex 6 .

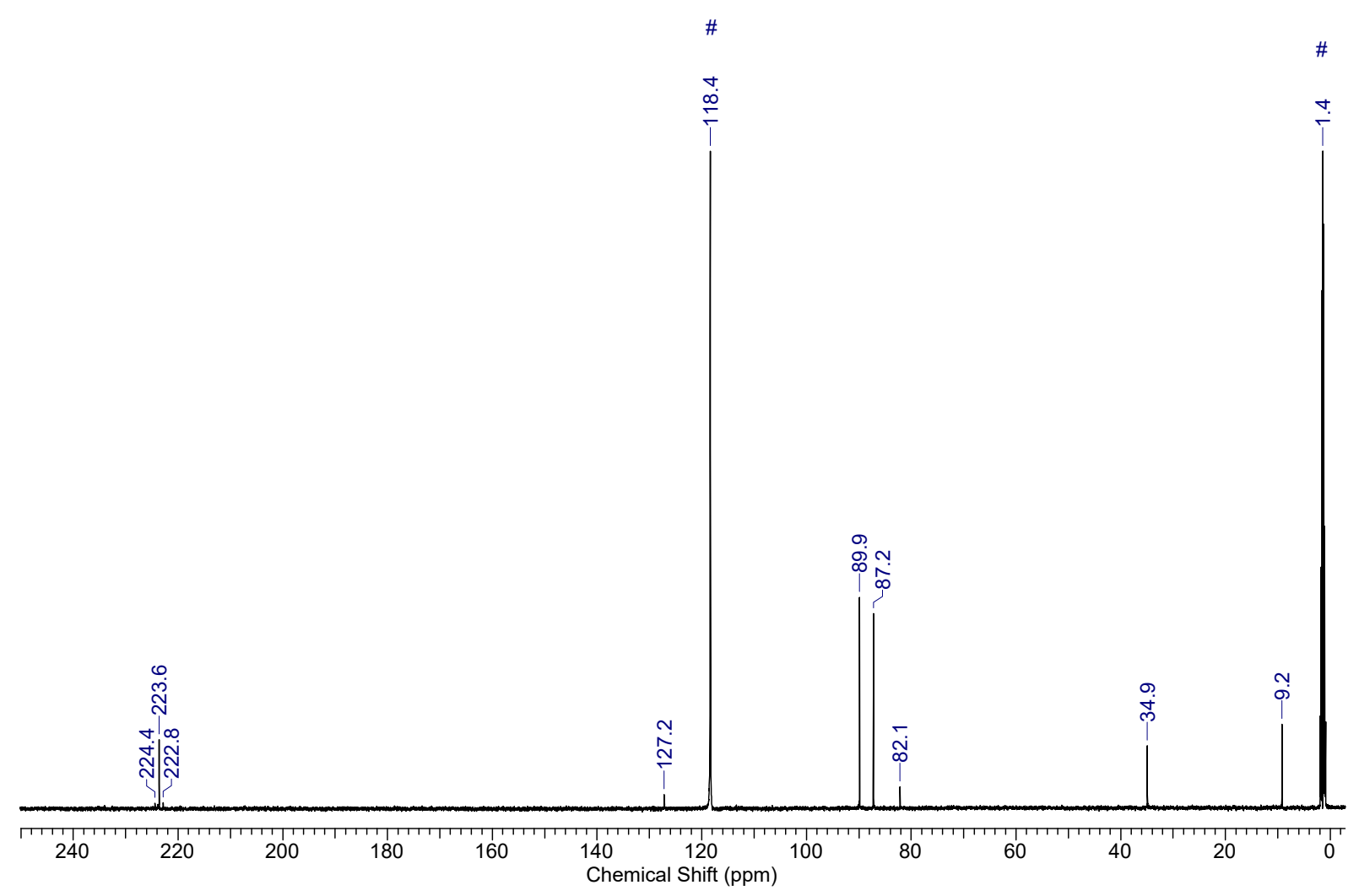

Figure S8. ${ }^{13} \mathrm{C}$ NMR spectrum $\left(126 \mathrm{MHz}, \mathrm{CD}_{3} \mathrm{CN} \#\right)$ of complex 6 . 


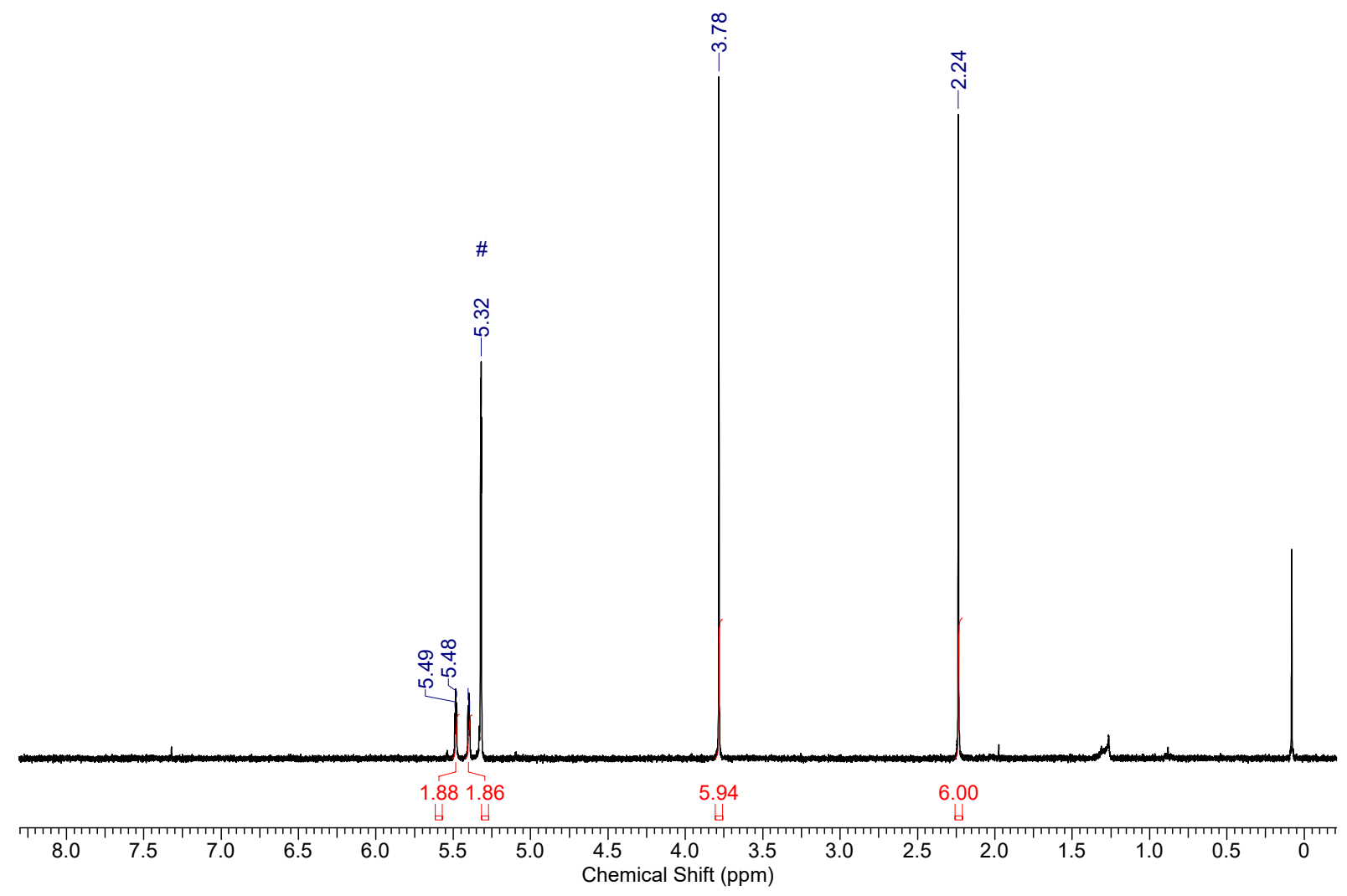

Figure S9. ${ }^{1} \mathrm{H}$ NMR spectrum $\left(400 \mathrm{MHz}, \mathrm{CD}_{2} \mathrm{Cl}_{2} \#\right)$ of complex 6 .

Spectra of complex 7
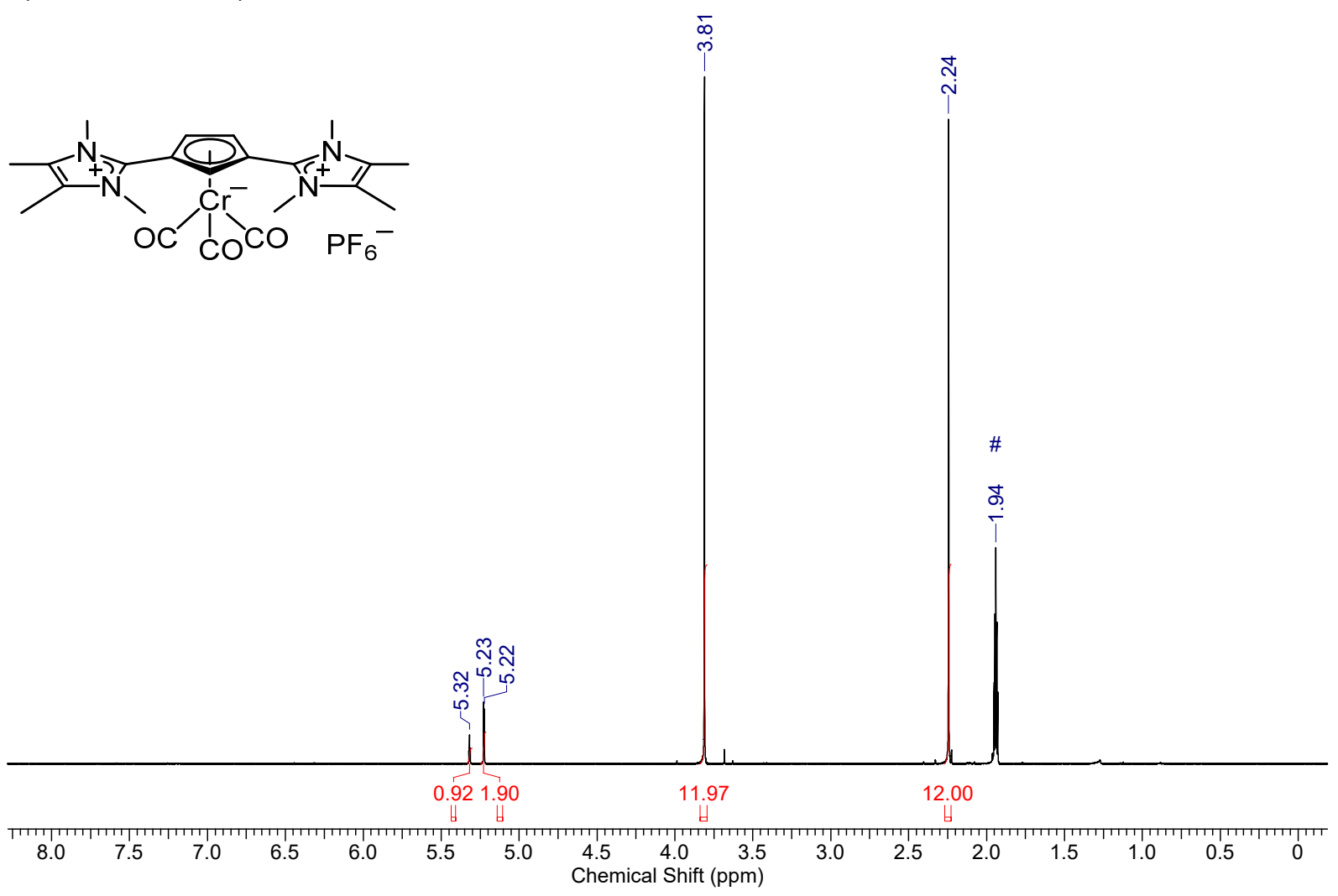

Figure S10. ${ }^{1} \mathrm{H}$ NMR spectrum (400 MHz, $\left.\mathrm{CD}_{3} \mathrm{CN} \#\right)$ of complex 7 . 


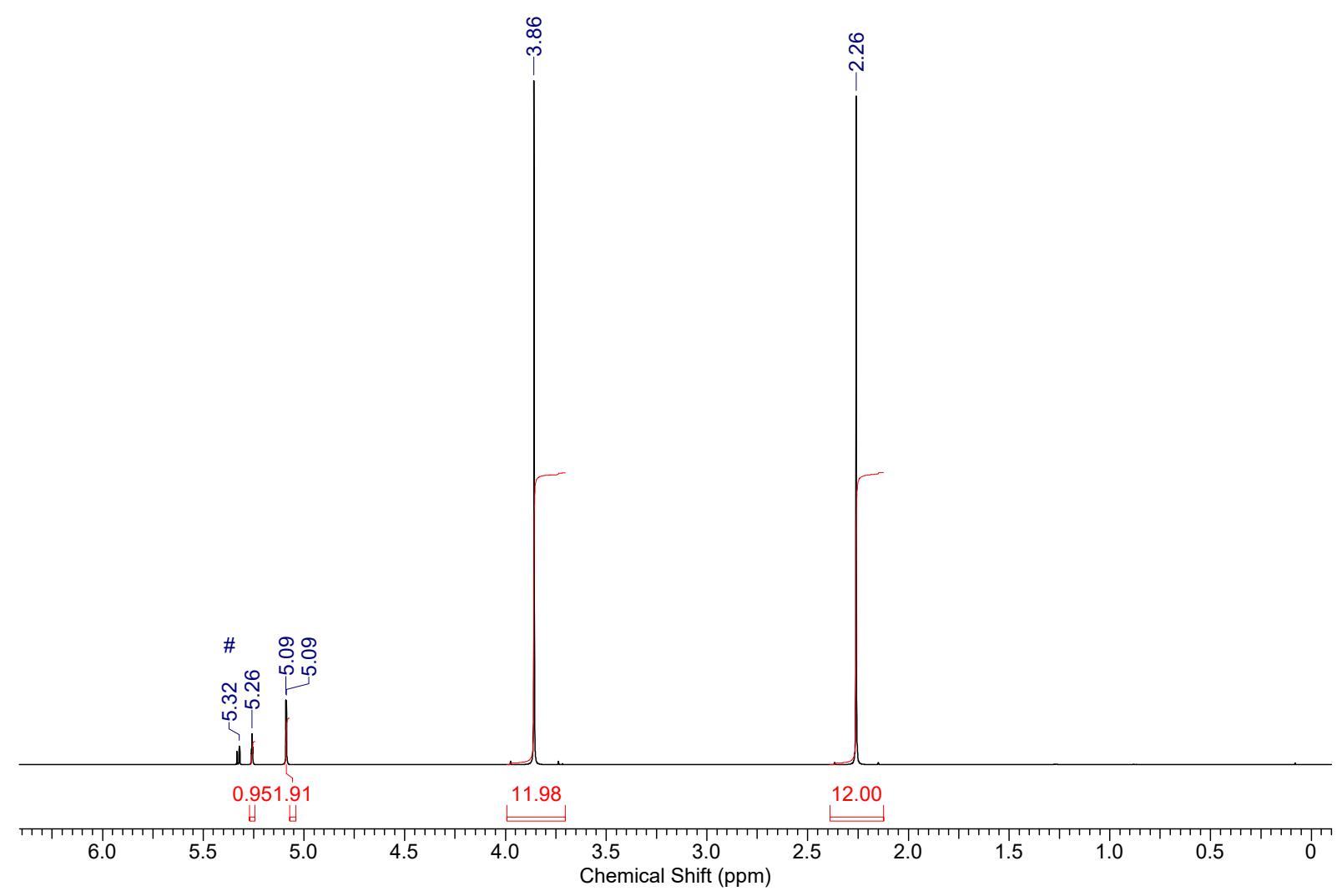

Figure S11. ${ }^{1} \mathrm{H}$ NMR spectrum $\left(600 \mathrm{MHz}, \mathrm{CD}_{2} \mathrm{Cl}_{2} \#\right)$ of complex 7 .

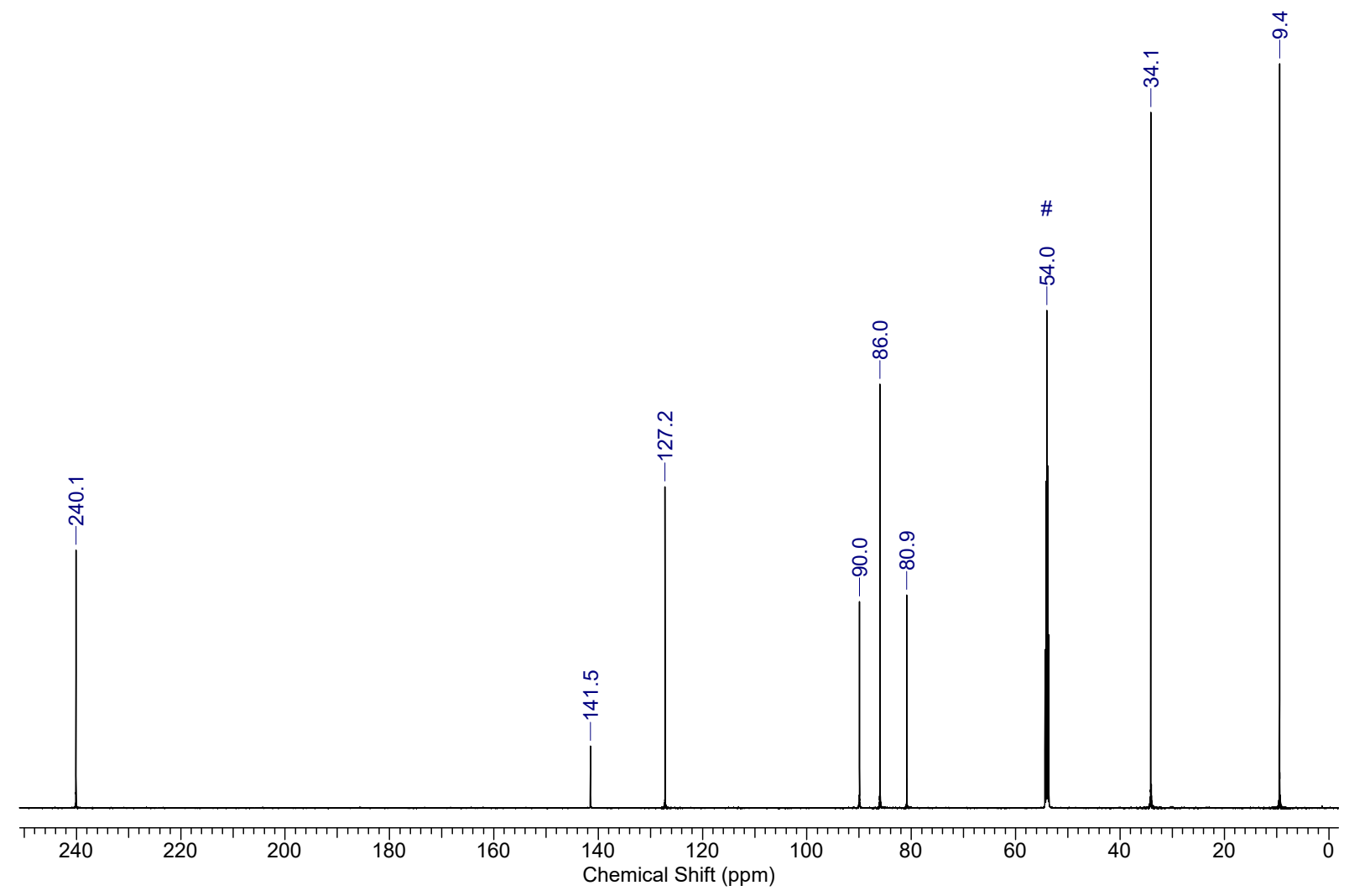

Figure S12. ${ }^{13} \mathrm{C}$ NMR spectrum $\left(151 \mathrm{MHz}, \mathrm{CD}_{2} \mathrm{Cl}_{2} \#\right)$ of complex 7. 
Spectra of complex 8
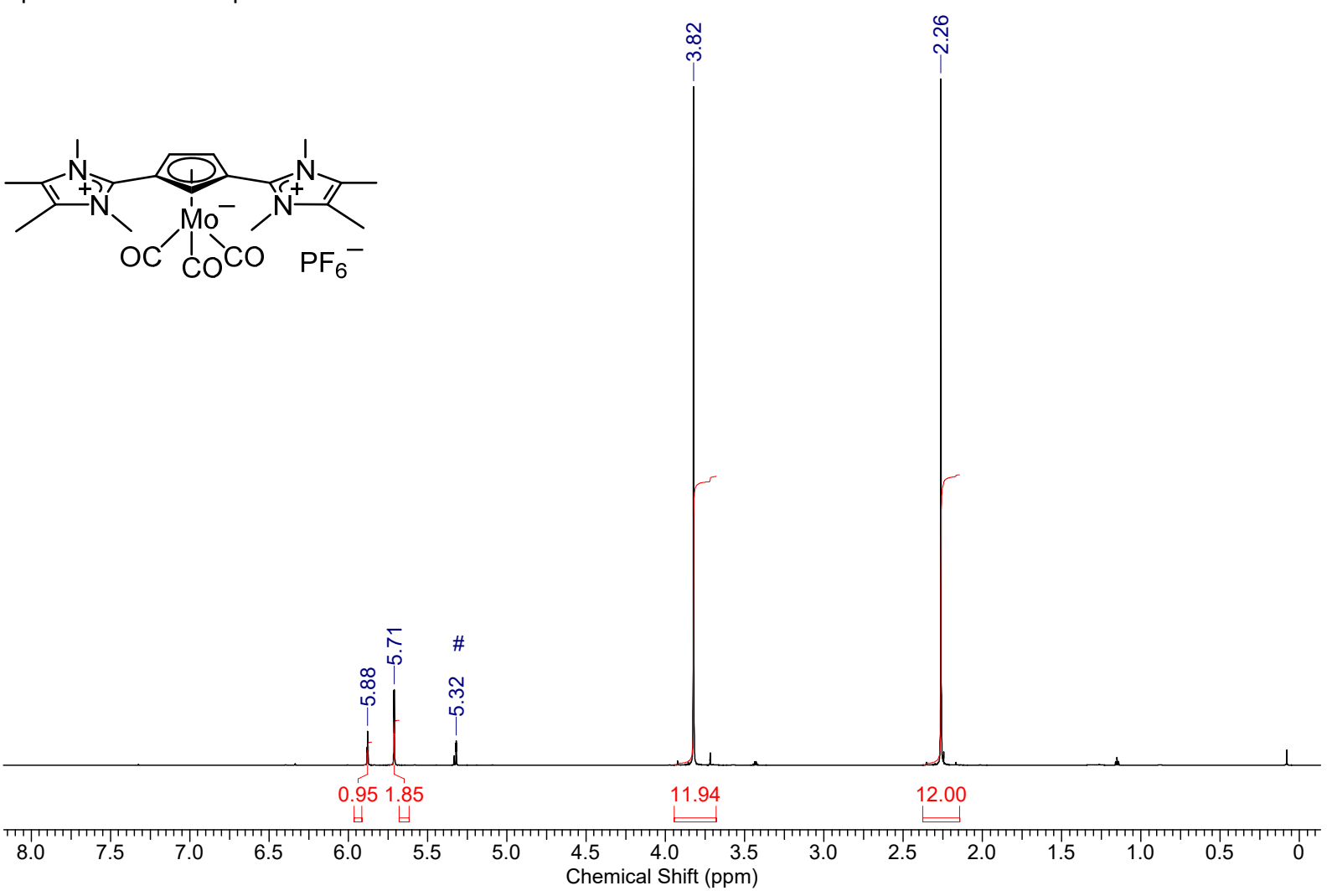

Figure S13: ${ }^{1} \mathrm{H}$ NMR spectrum $\left(700 \mathrm{MHz}, \mathrm{CD}_{2} \mathrm{Cl}_{2} \#\right)$ of complex 8 .

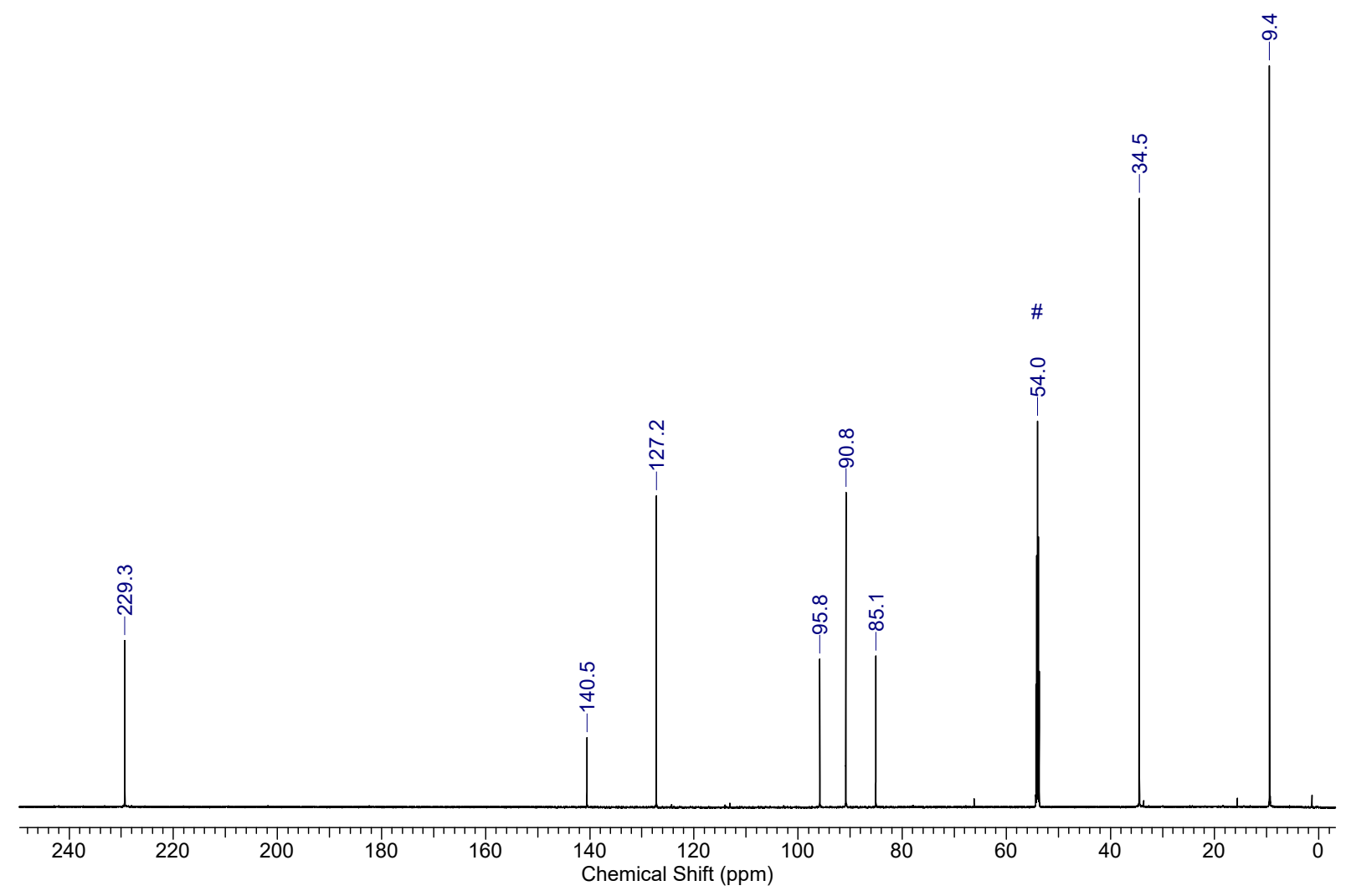

Figure S14. ${ }^{13} \mathrm{C}$ NMR spectrum $\left(176 \mathrm{MHz}, \mathrm{CD}_{2} \mathrm{Cl}_{2} \#\right)$ of complex 8. 
Spectra of complex 9
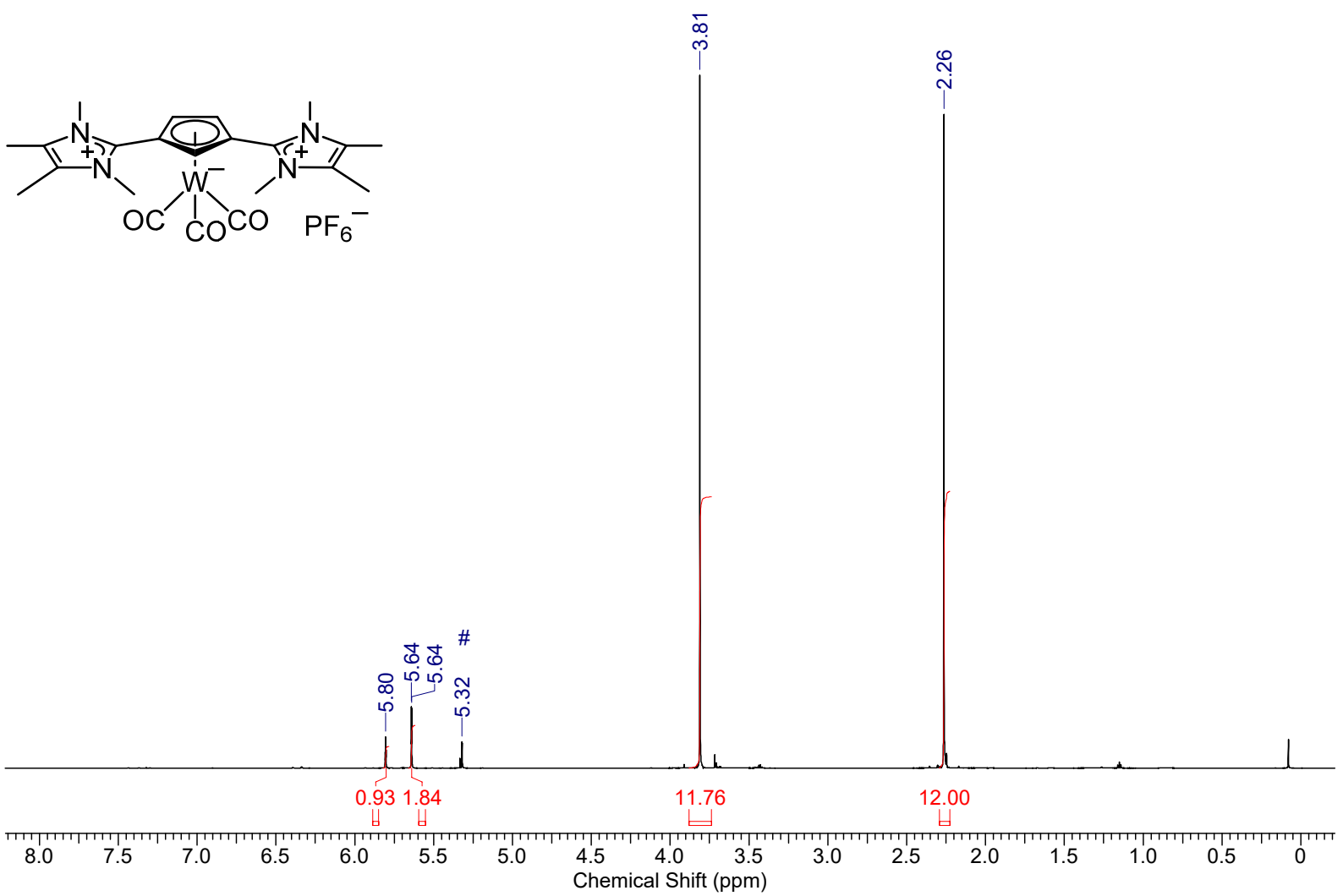

Figure S15. ${ }^{1} \mathrm{H}$ NMR spectrum $\left(700 \mathrm{MHz}, \mathrm{CD}_{2} \mathrm{Cl}_{2} \#\right)$ of complex 9 .

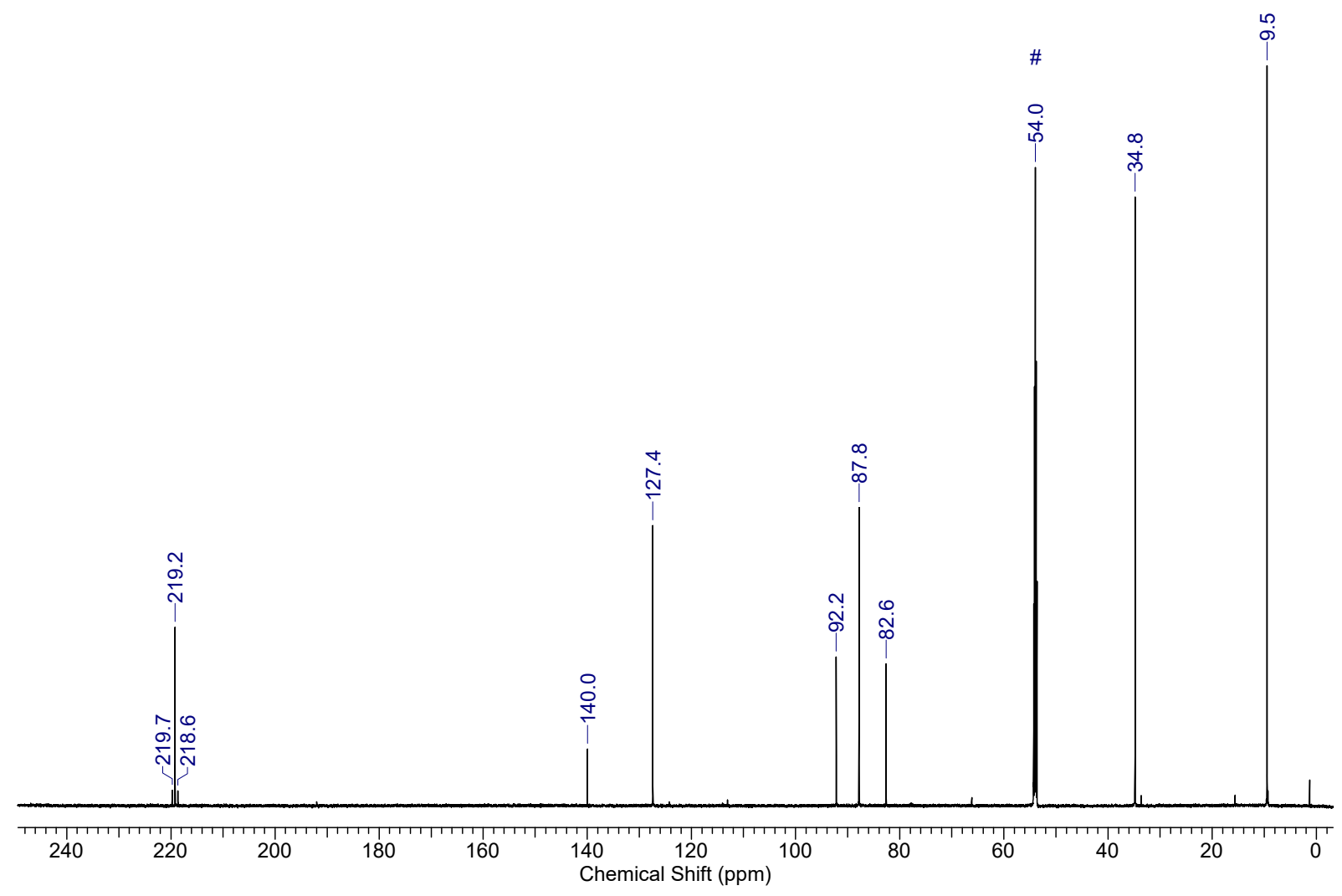

Figure S16. ${ }^{13} \mathrm{C}$ NMR spectrum $\left(176 \mathrm{MHz}, \mathrm{CD}_{2} \mathrm{Cl}_{2} \#\right)$ of complex 9. 
Spectra of complex 10

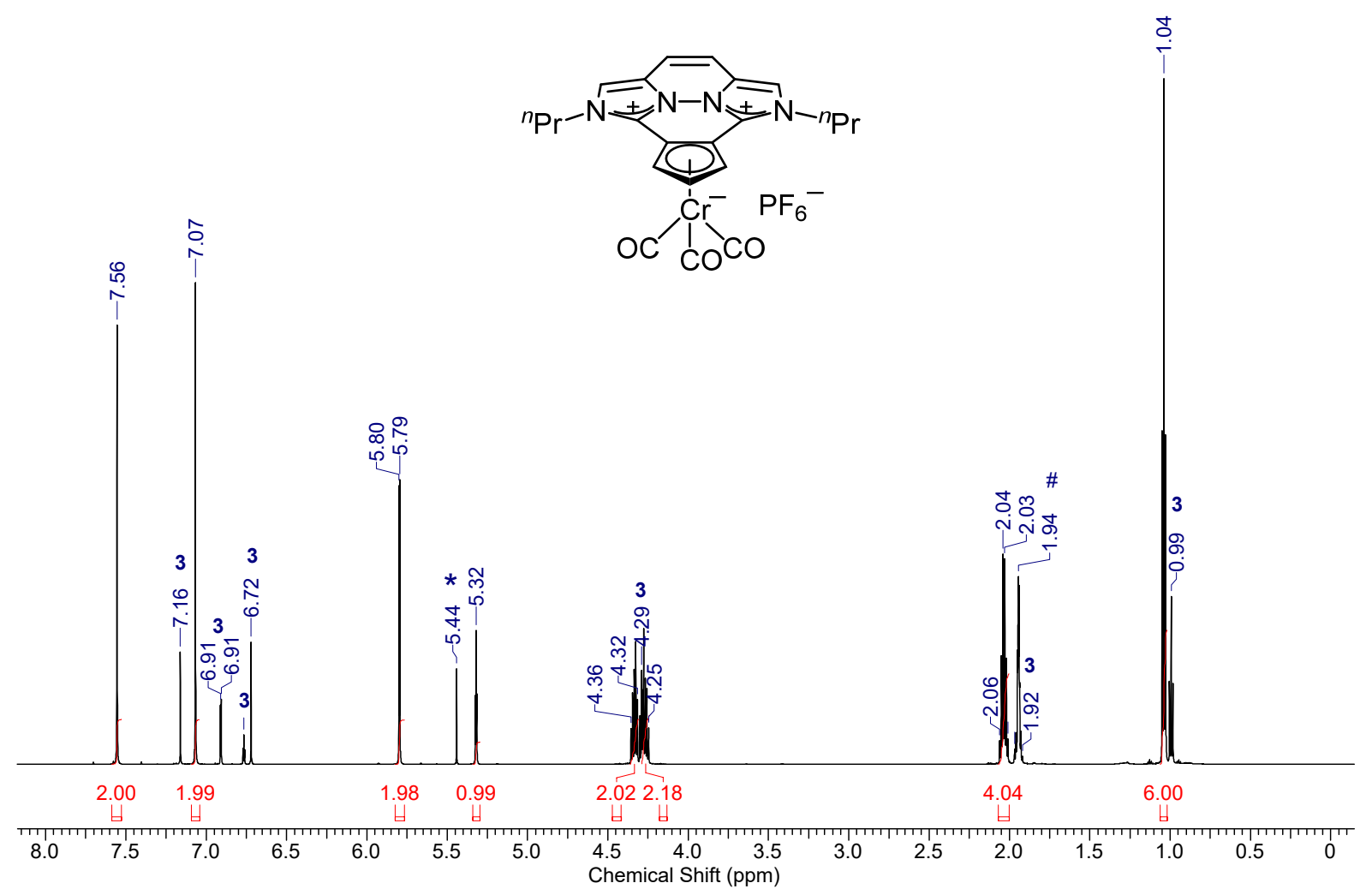

Figure S17. ${ }^{1} \mathrm{H}$ NMR spectrum $\left(700 \mathrm{MHz}, \mathrm{CD}_{3} \mathrm{CN} \#\right)$ of complex 10 . Solvolysis leads to free ligand 3 (dichloromethane *).

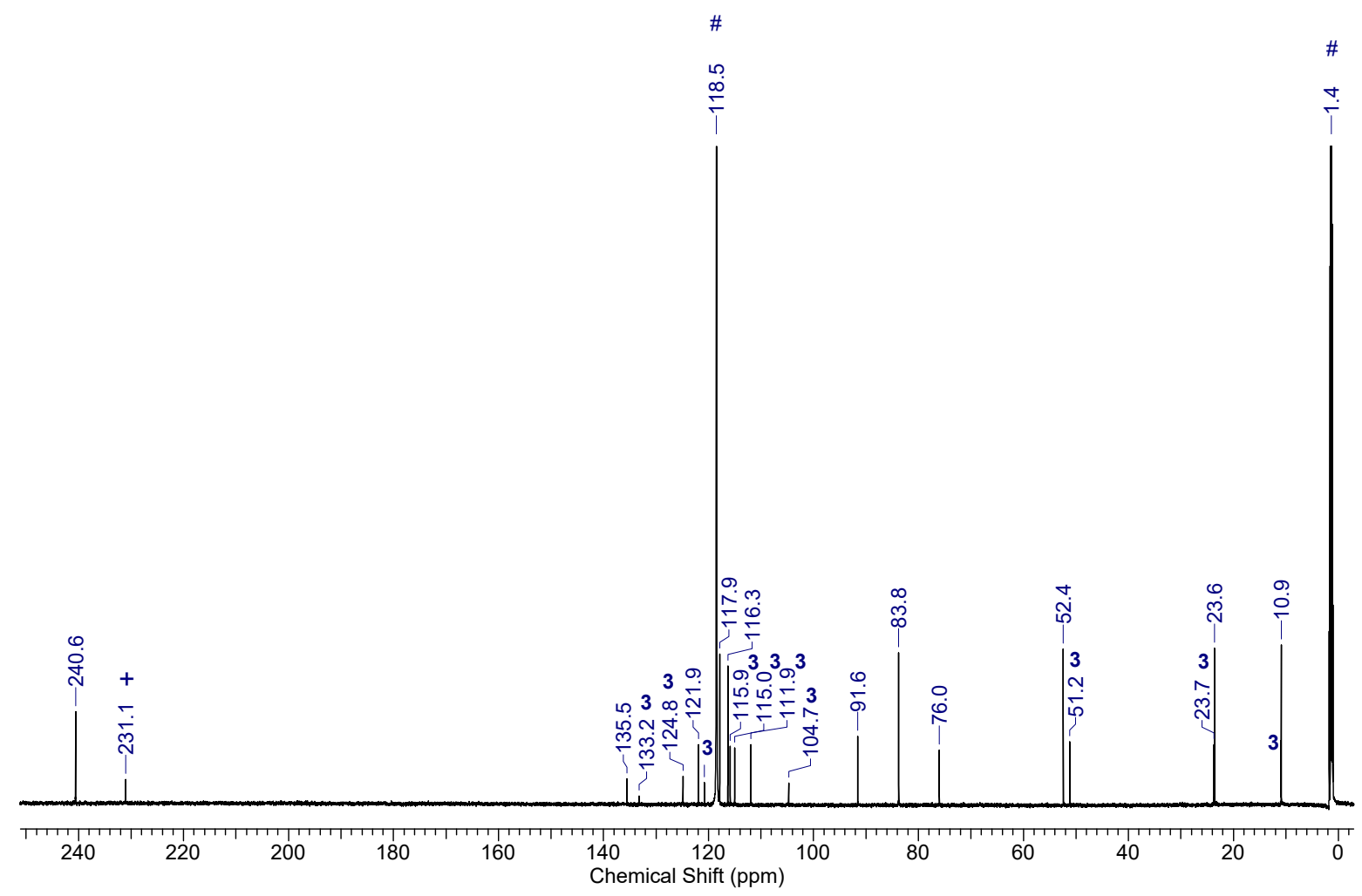

Figure S18. ${ }^{1} \mathrm{H}$ NMR spectrum $\left(700 \mathrm{MHz}, \mathrm{CD}_{3} \mathrm{CN} \#\right)$ of complex $\mathbf{1 0}$. Solvolysis leads to free ligand $\mathbf{3}$ and $\left[\mathrm{Cr}\left(\mathrm{CD}_{3} \mathrm{CN}\right)(\mathrm{CO})_{3}\right]+$. 
Spectra of the mixture of the isomers 13 and 14

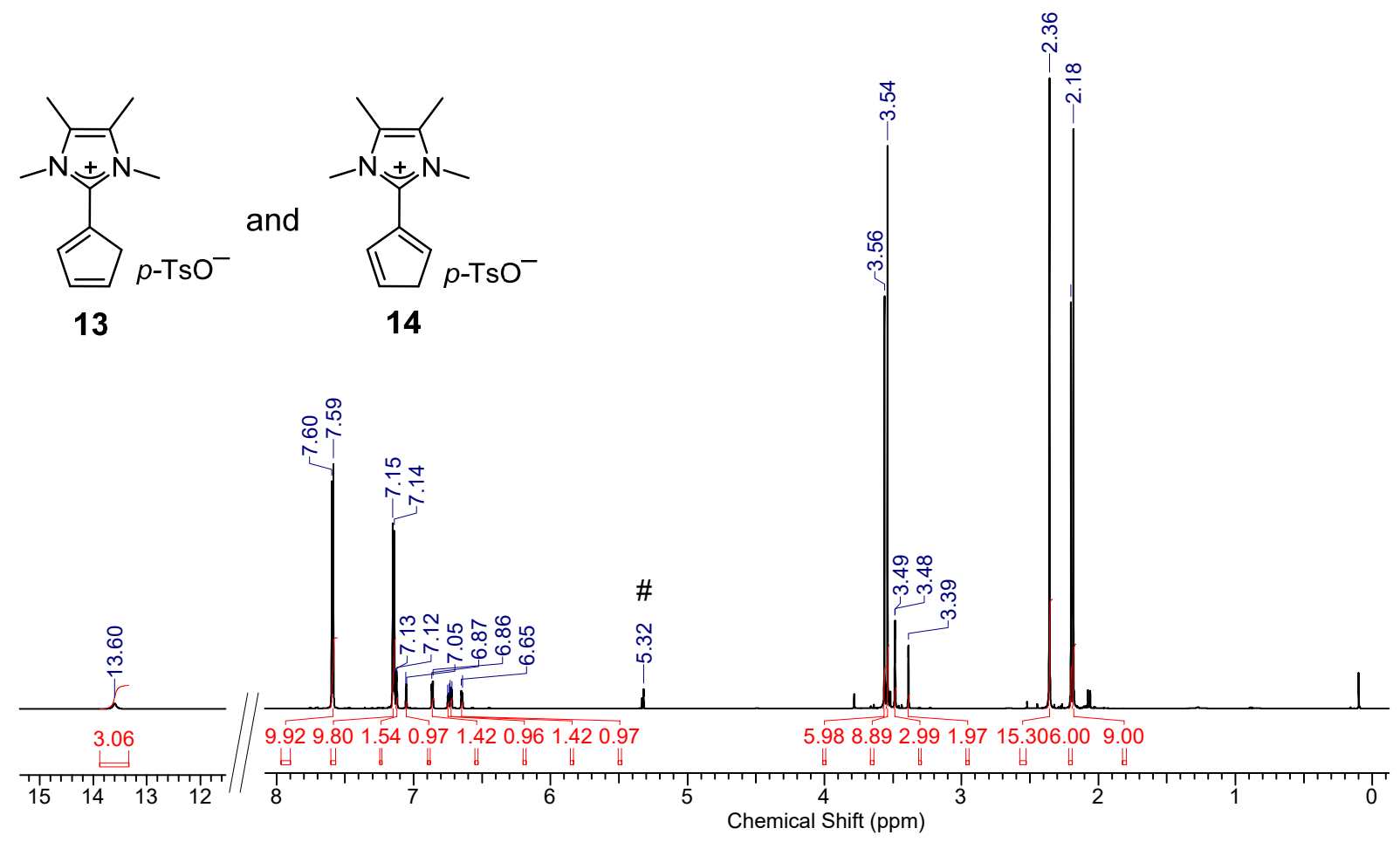

Figure S19. ${ }^{1} \mathrm{H}$ NMR spectrum $\left(700 \mathrm{MHz}, \mathrm{CD}_{2} \mathrm{Cl}_{2} \#\right)$ of the mixture of the isomers 13 and 14.

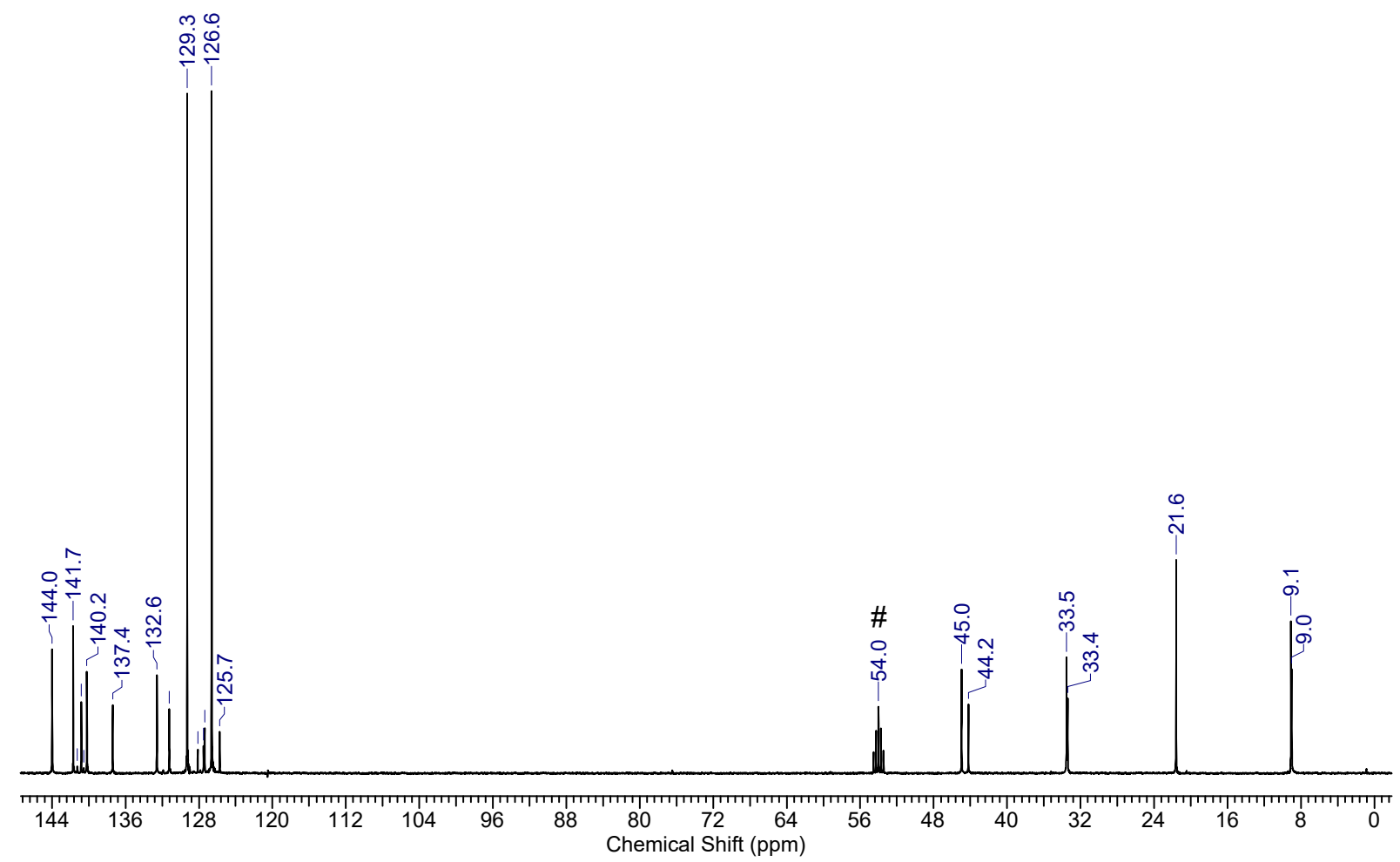

Figure S20. ${ }^{13} \mathrm{C}$ NMR spectrum $\left(176 \mathrm{MHz}, \mathrm{CD}_{2} \mathrm{Cl}_{2} \#\right)$ of the mixture of the isomers $\mathbf{1 3}$ and $\mathbf{1 4 .}$ 
Spectra of the mixture of the isomers 15 and 16

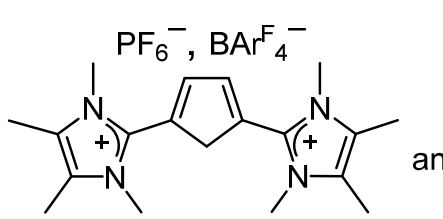

15<smiles></smiles>

16

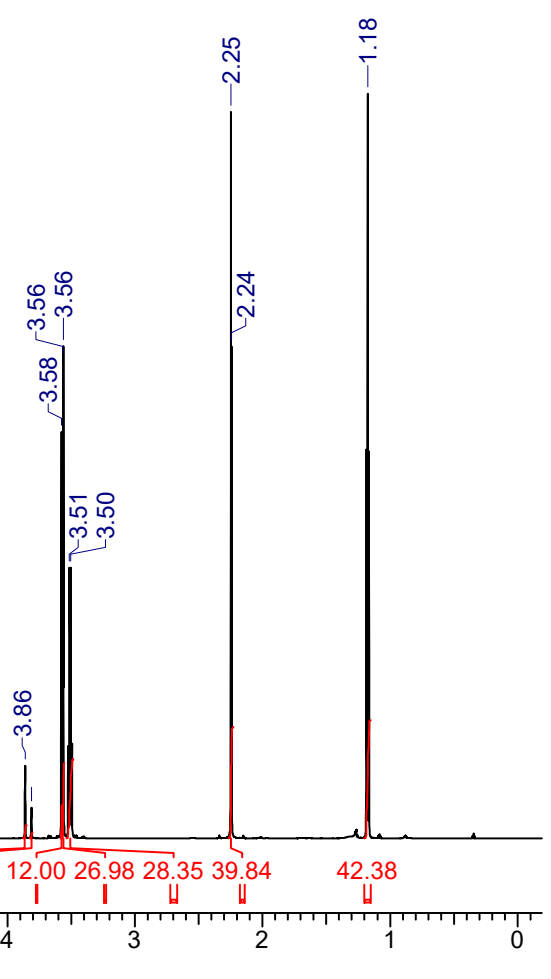

Figure S21. ${ }^{1} \mathrm{H}$ NMR spectrum $\left(700 \mathrm{MHz}, \mathrm{CD}_{2} \mathrm{Cl}_{2} \#\right)$ of the mixture of the isomers 15 and 16.

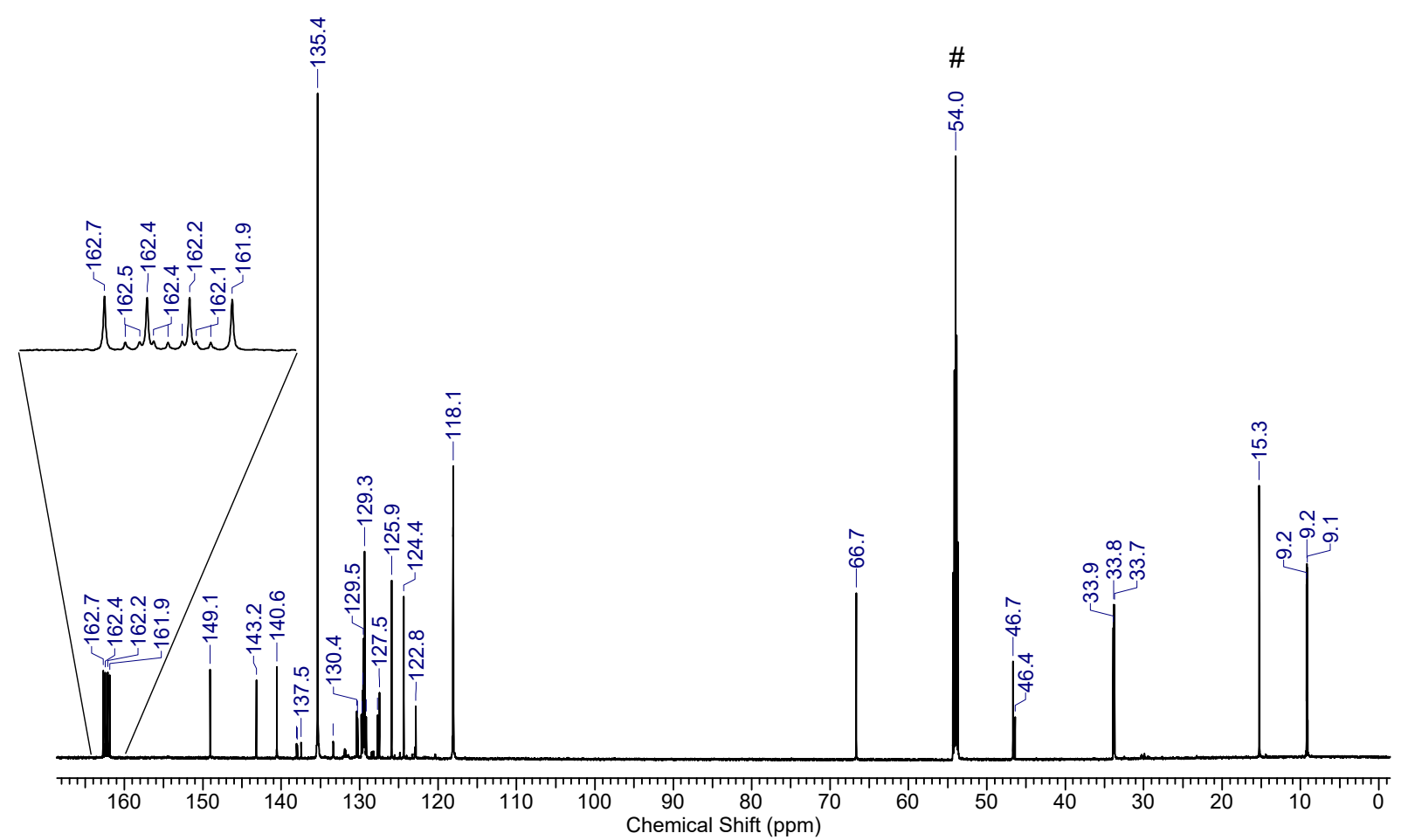

Figure S22. ${ }^{13} \mathrm{C}$ NMR spectrum $\left(176 \mathrm{MHz}, \mathrm{CD}_{2} \mathrm{Cl}_{2} \#\right)$ of the mixture of the isomers $\mathbf{1 5}$ and $\mathbf{1 6}$. 
Spectra of compound 2 with 2 equiv. of $p$-TsOH

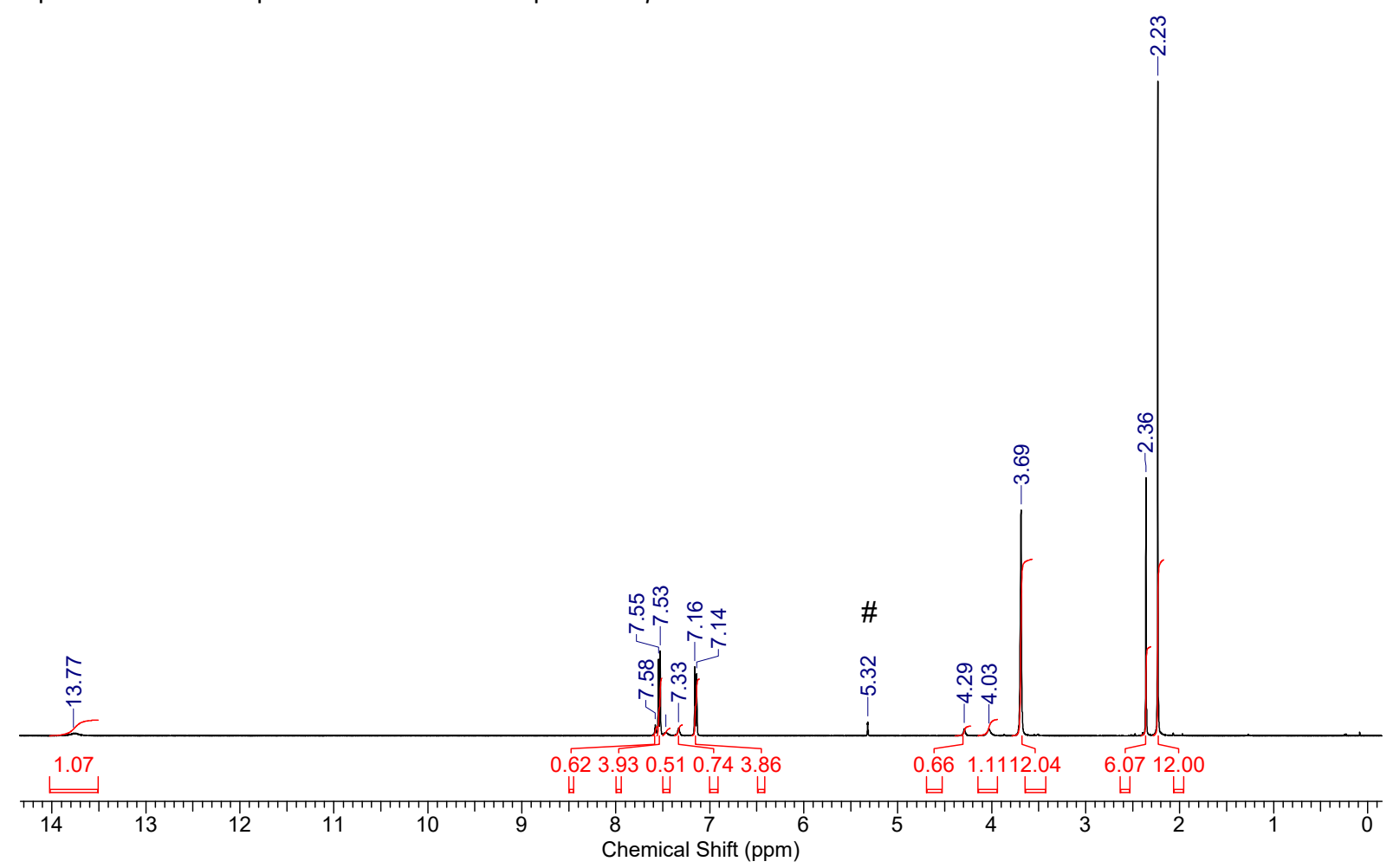

Figure S23. ${ }^{1} \mathrm{H}$ NMR spectrum ( $400 \mathrm{MHz}, \mathrm{CD}_{2} \mathrm{Cl}_{2} \#$ ) of compound 2 with 2 equiv. of $p$-TsOH.

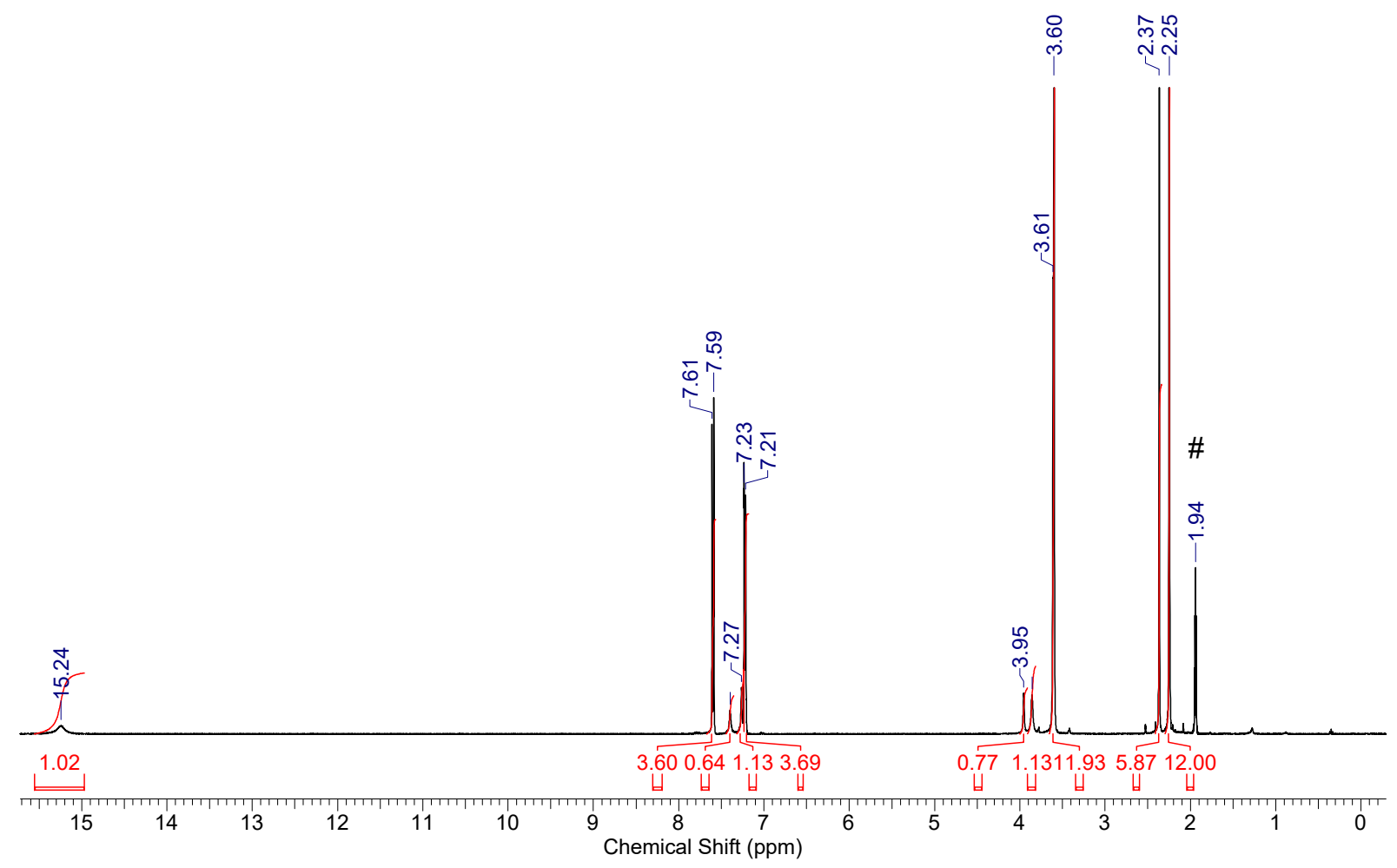

Figure S24. ${ }^{1} \mathrm{H}$ NMR spectrum $\left(400 \mathrm{MHz}, \mathrm{CD}_{3} \mathrm{CN} \#\right)$ of compound 2 with 2 equiv. of $p$-TsOH. 


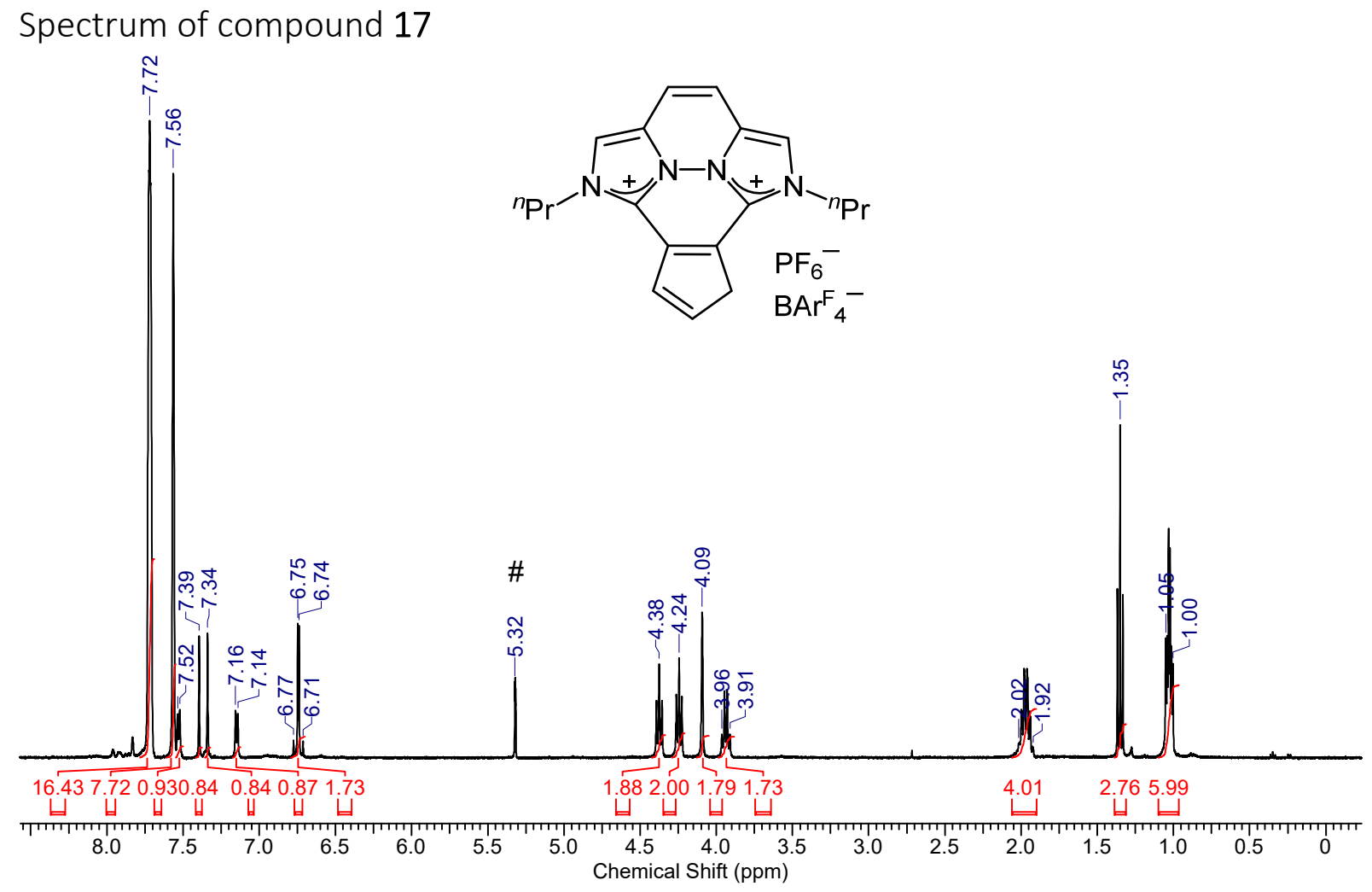

Figure S25. ${ }^{1} \mathrm{H}$ NMR spectrum $\left(400 \mathrm{MHz}, \mathrm{CD}_{2} \mathrm{Cl}_{2} \#\right)$ of compound 17.

Spectra of compound 3 with 2 equiv. of $p$ - $\mathrm{TsOH}$

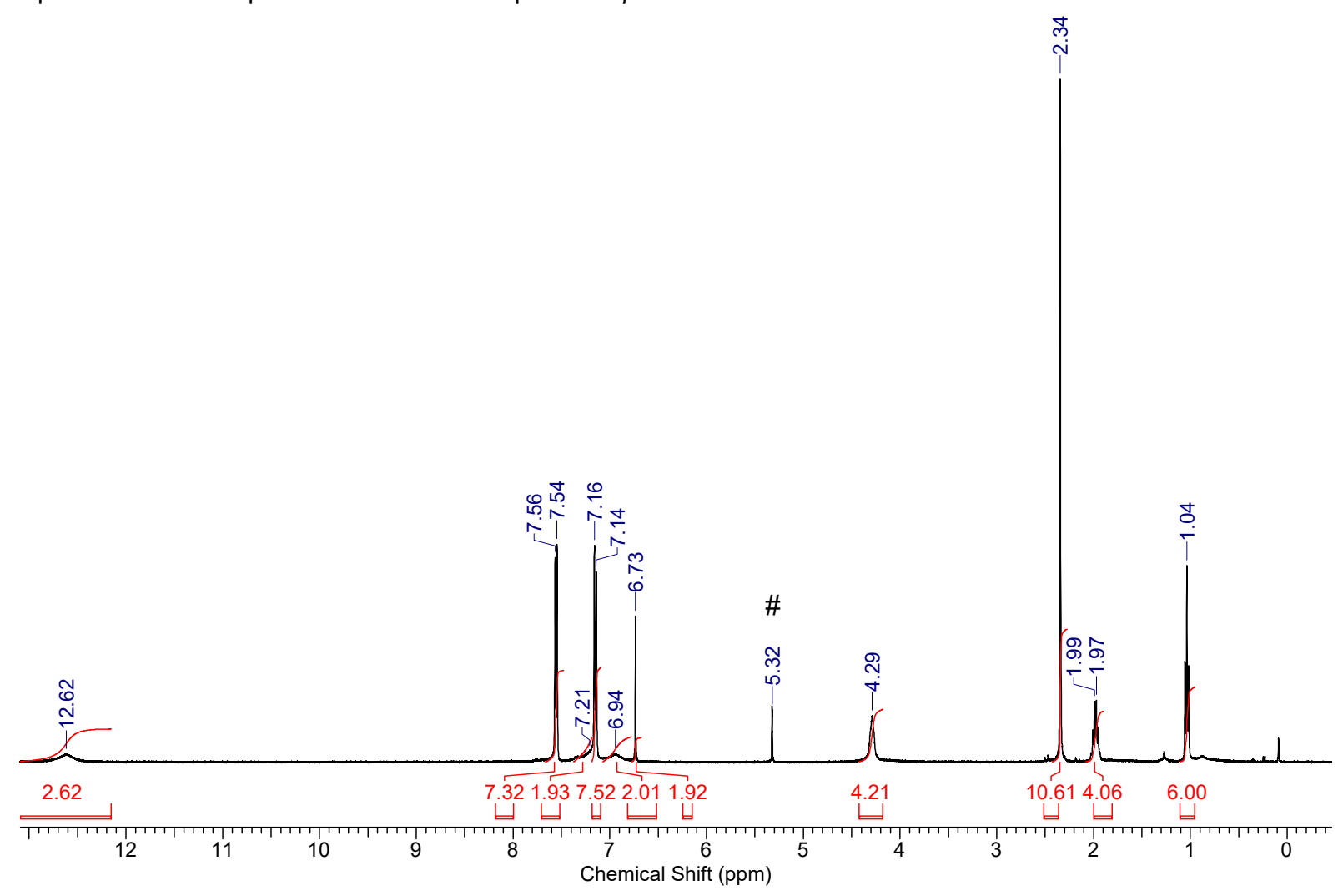

Figure S26. ${ }^{1} \mathrm{H}$ NMR spectrum $\left(400 \mathrm{MHz}, \mathrm{CD}_{2} \mathrm{Cl}_{2} \#\right)$ of compound 3 with 2 equiv. of $p$-TsOH. 


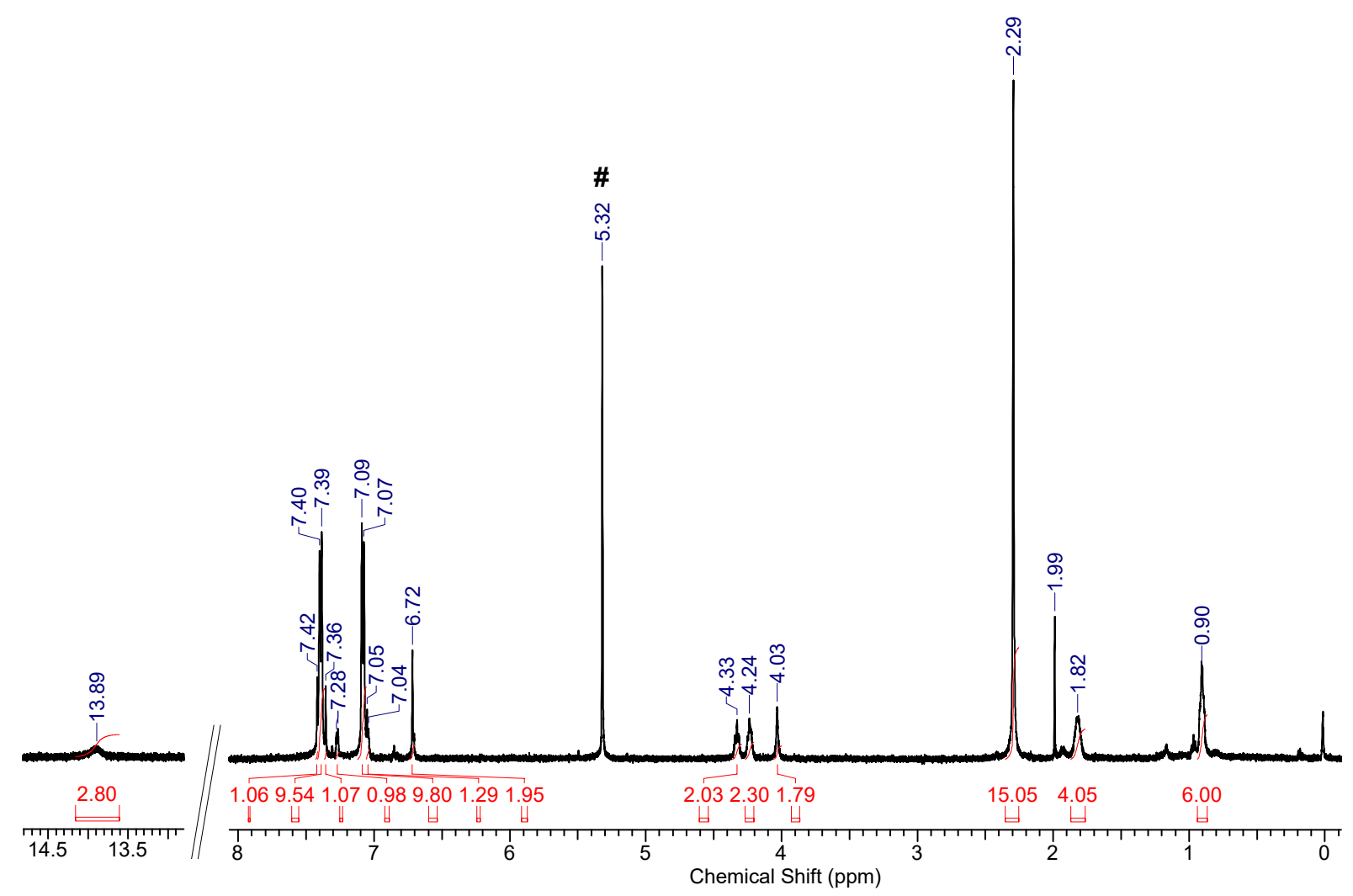

Figure S27. ${ }^{1} \mathrm{H}$ NMR spectrum $\left(500 \mathrm{MHz}, \mathrm{CD}_{2} \mathrm{Cl}_{2} \#\right)$ of compound $\mathbf{3}$ with 2 equiv. of $p$-TsOH at $-60{ }^{\circ} \mathrm{C}$.

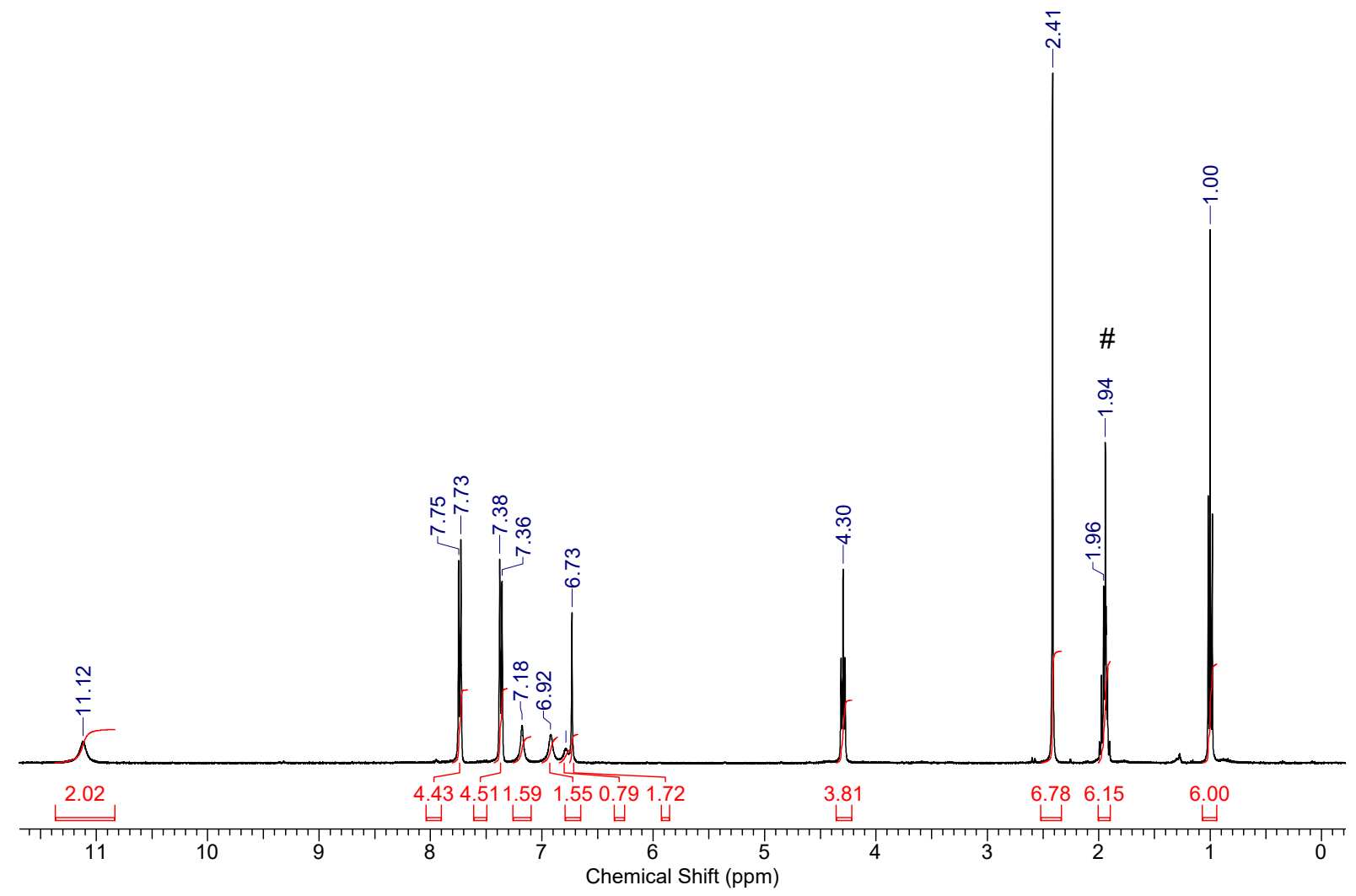

Figure S28. ${ }^{1} \mathrm{H}$ NMR spectrum $\left(400 \mathrm{MHz}, \mathrm{CD}_{3} \mathrm{CN} \#\right)$ of compound 3 with 2 equiv. of $p$-TsOH. 


\section{IR spectra}

Due to removal of the company logo, the ATR spectra are cut off above $3200 \mathrm{~cm}^{-1}$.

Spectra of complex 4

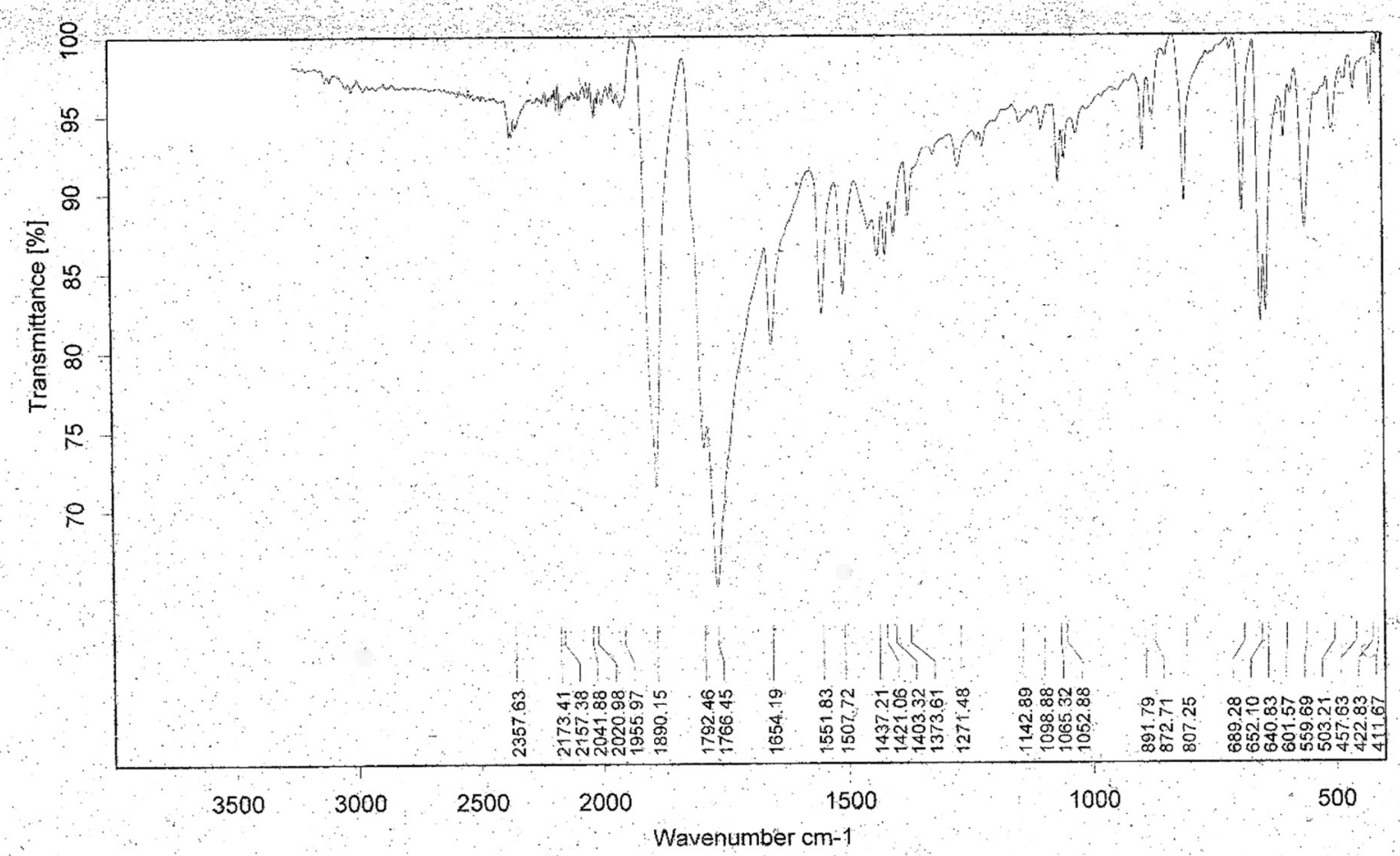

Figure S29. IR spectrum (ATR) of complex 4.

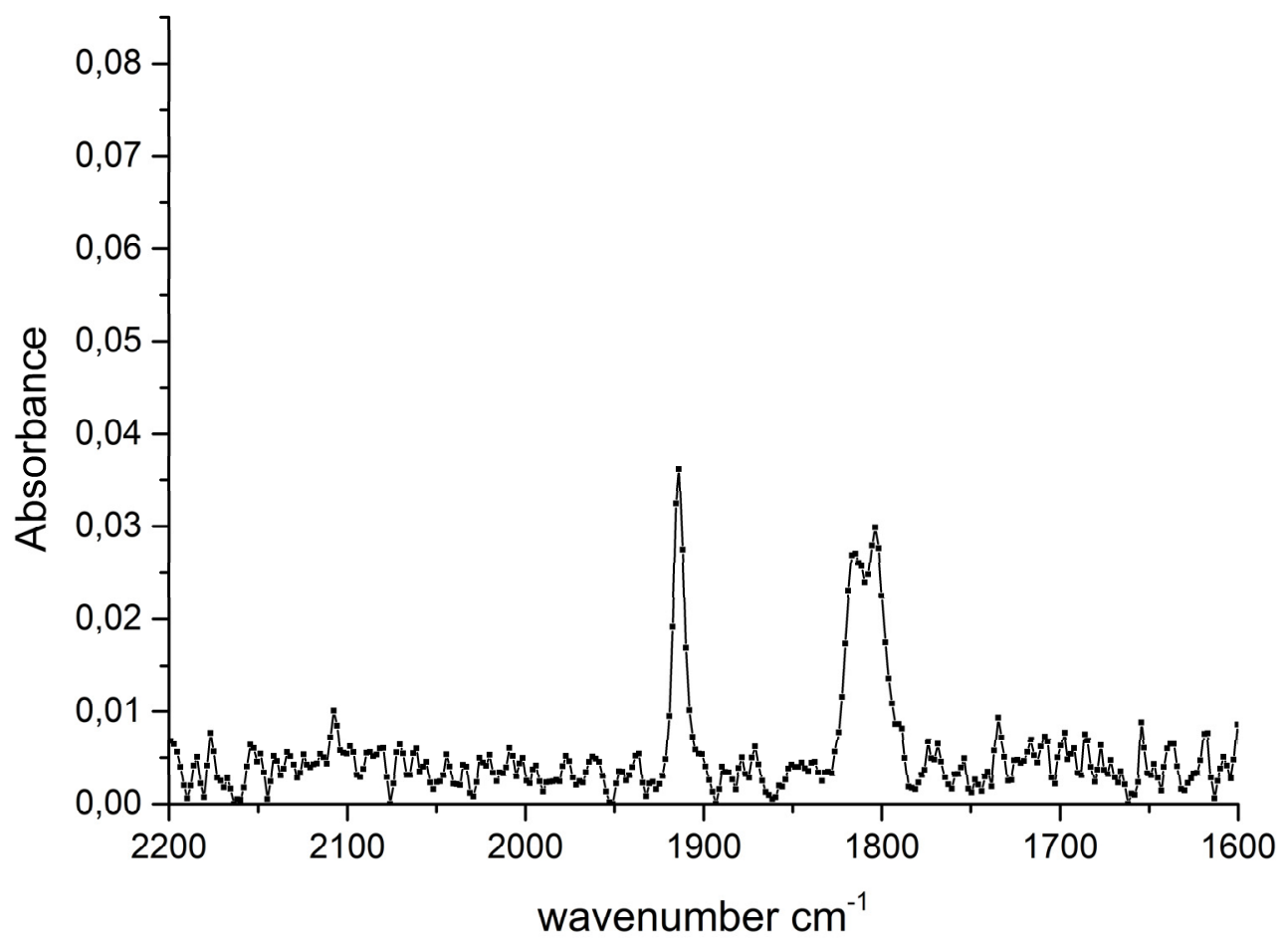

Figure S30. IR spectrum (tetrahydrofuran) of complex 4. 


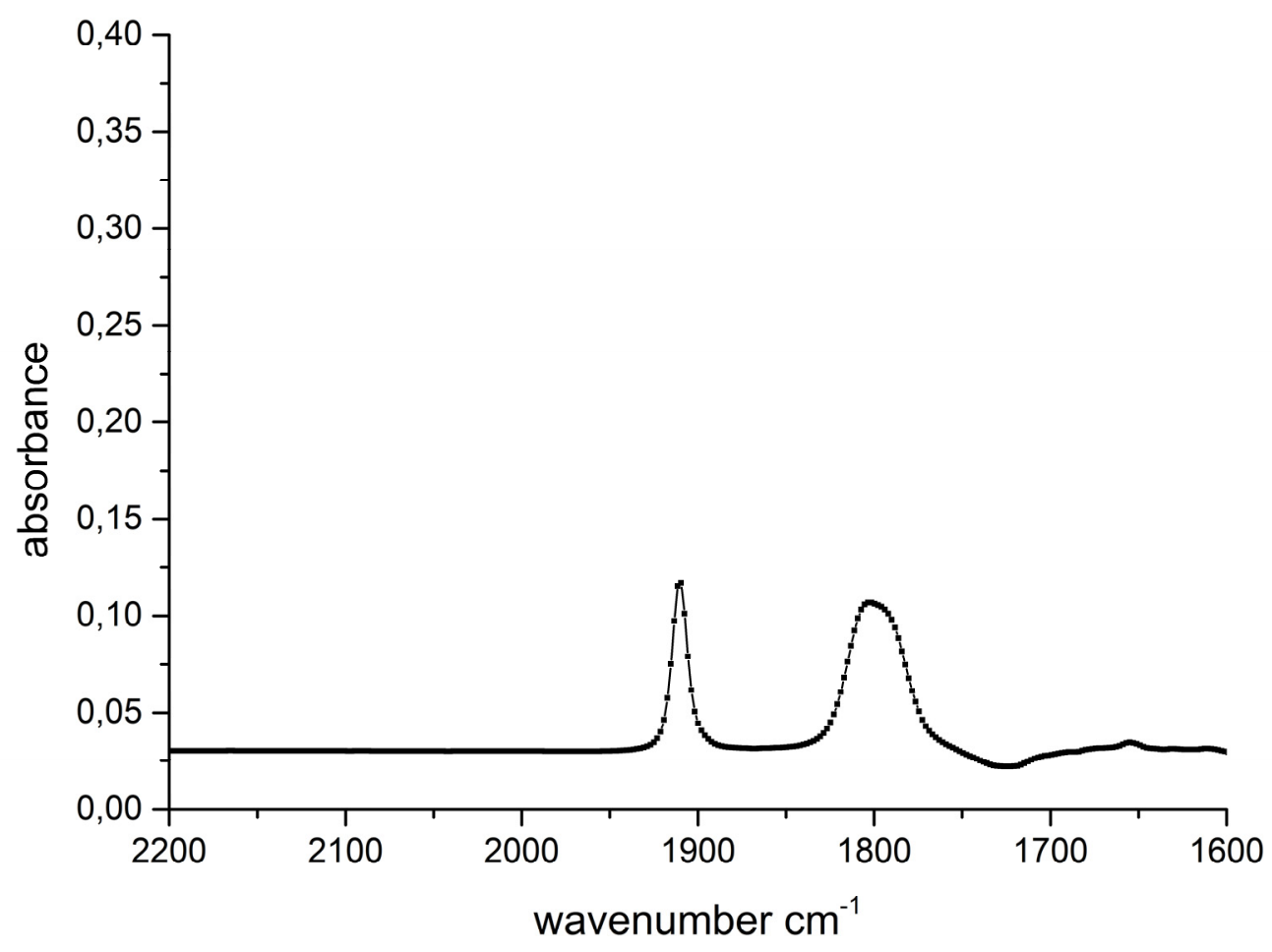

Figure S31. IR spectrum (dichloromethane) of complex 4.

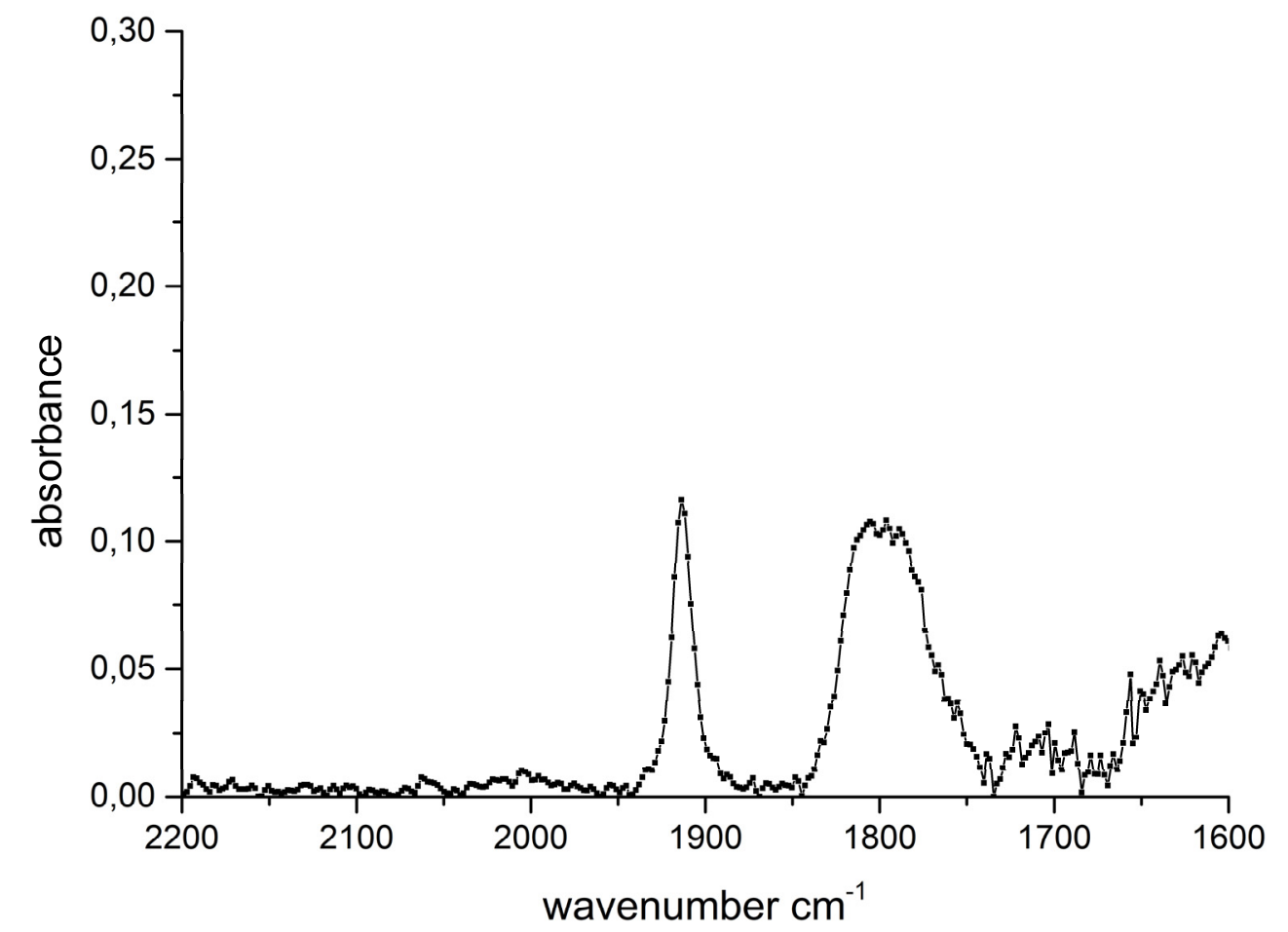

Figure S32. IR spectrum (chloroform) of complex 4. 
Spectrum of complex 5

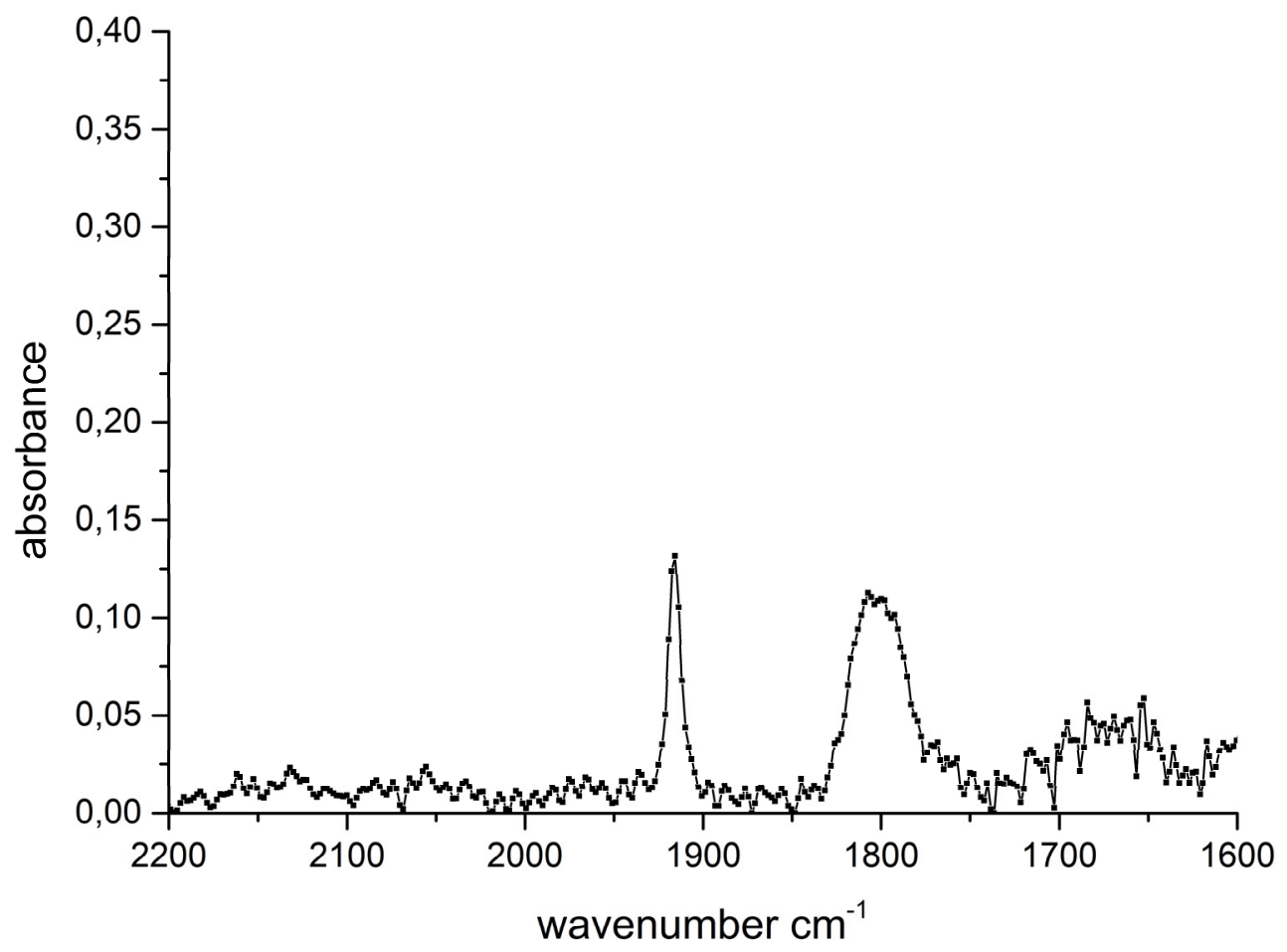

Figure S33. IR spectrum (dichloromethane) of complex 5.

Spectra of complex 6

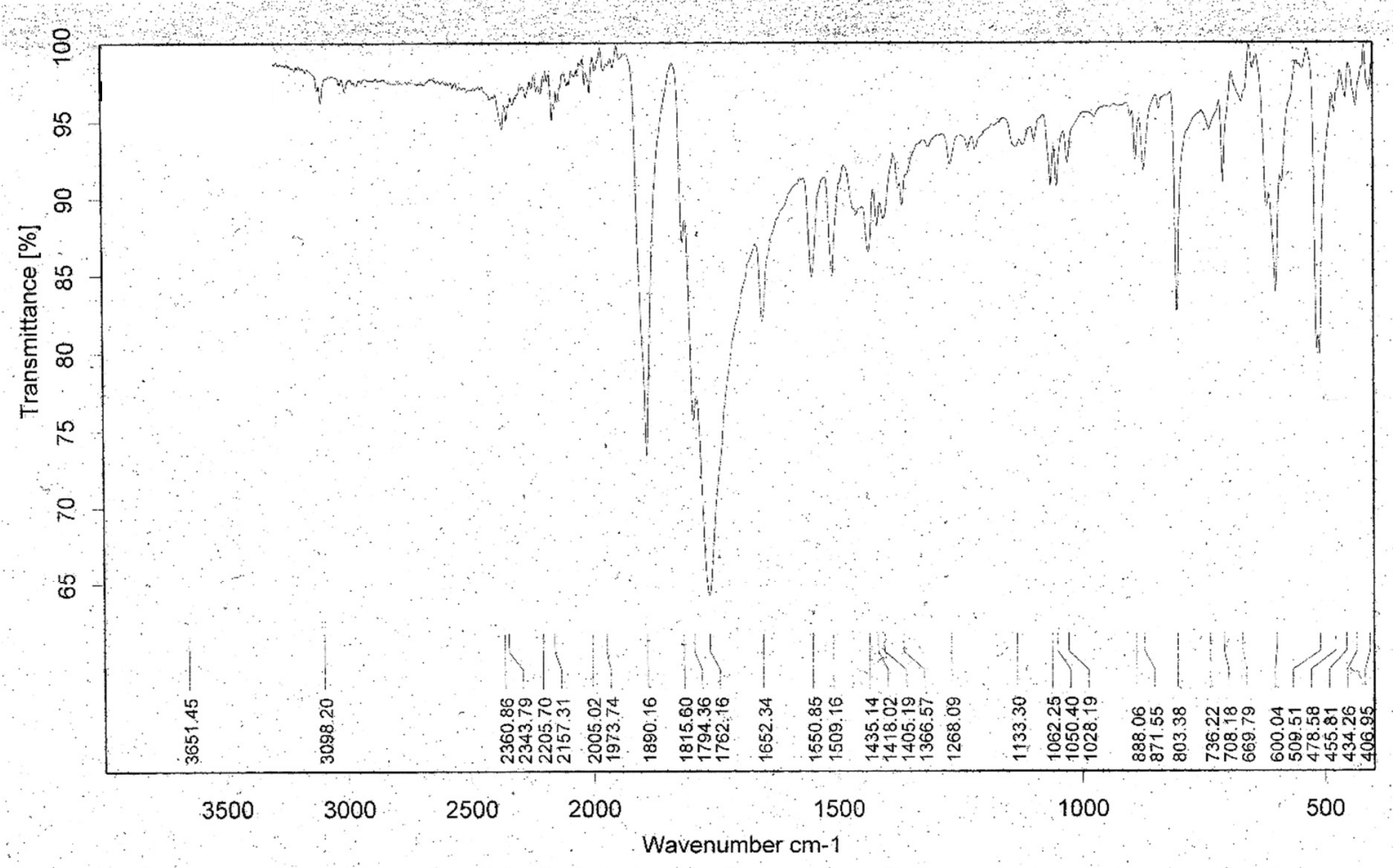

Figure S34. IR spectrum (ATR) of complex 6. 


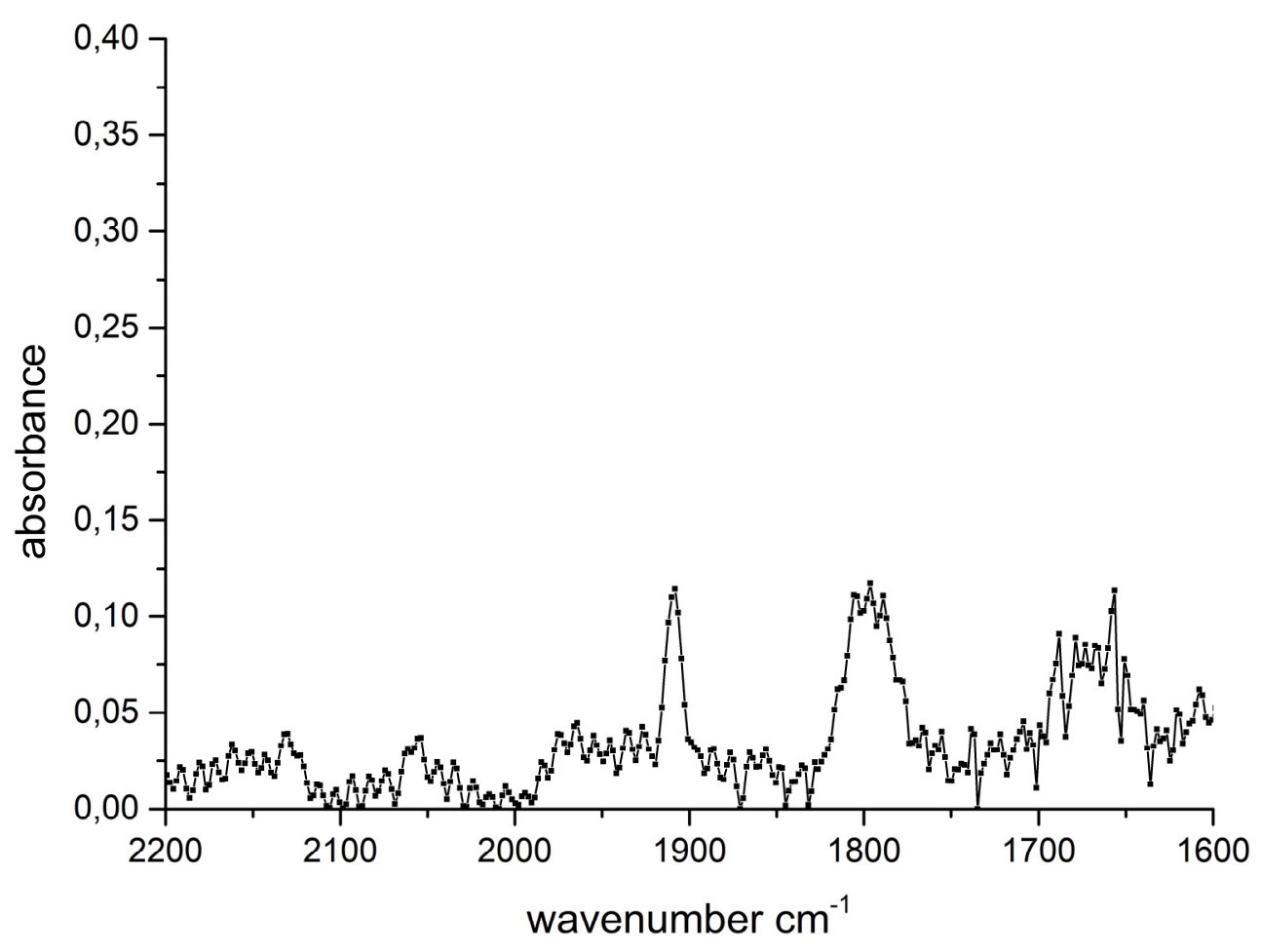

Figure S35. IR spectrum (dichloromethane) of complex 6 .

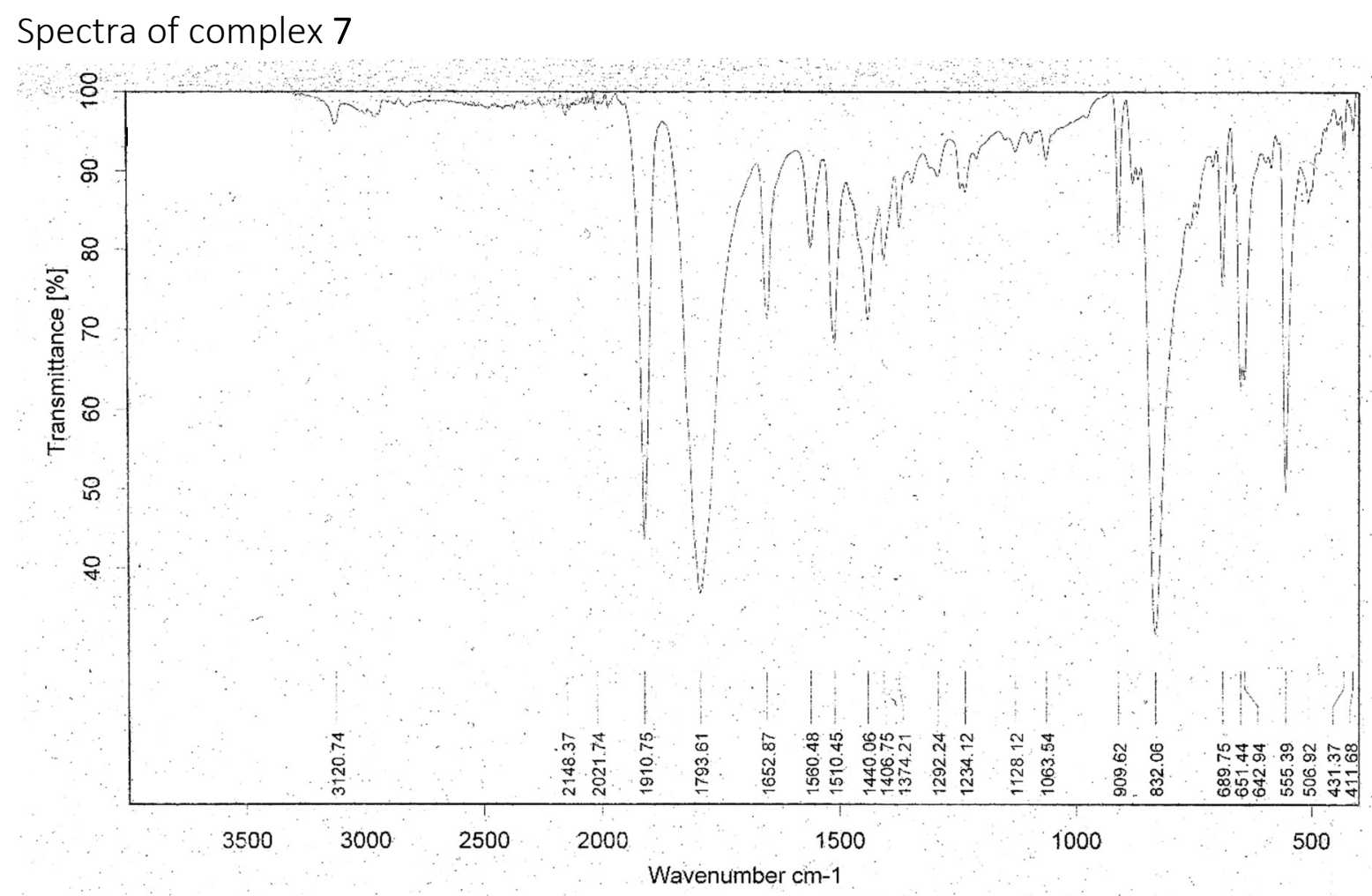

Figure S36. IR spectrum (ATR) of complex 7. 


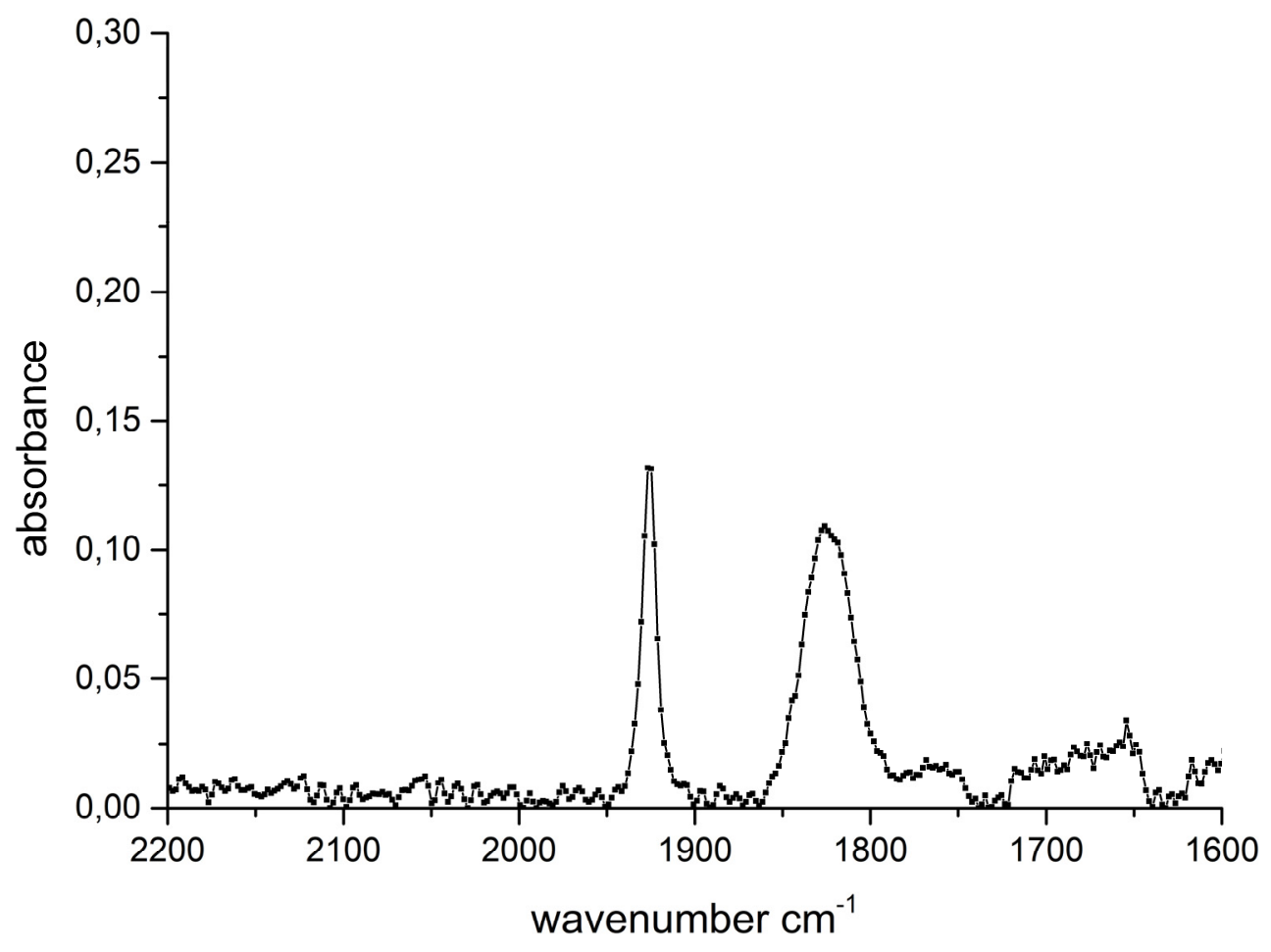

Figure S37. IR spectrum (dichloromethane) of complex 7.

Spectrum of complex 8

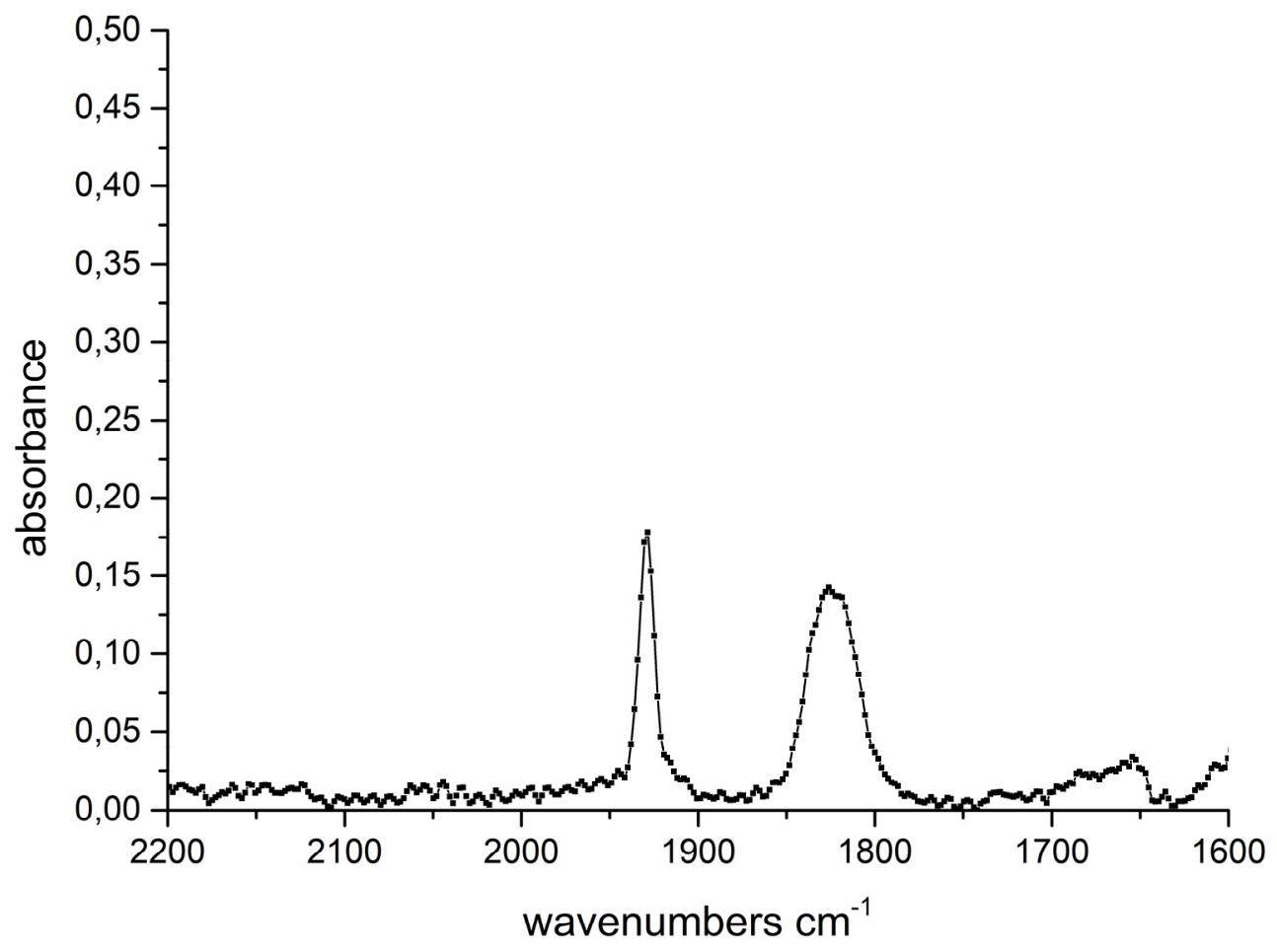

Figure S38. IR spectrum (dichloromethane) of complex 8. 
Spectrum of complex 9

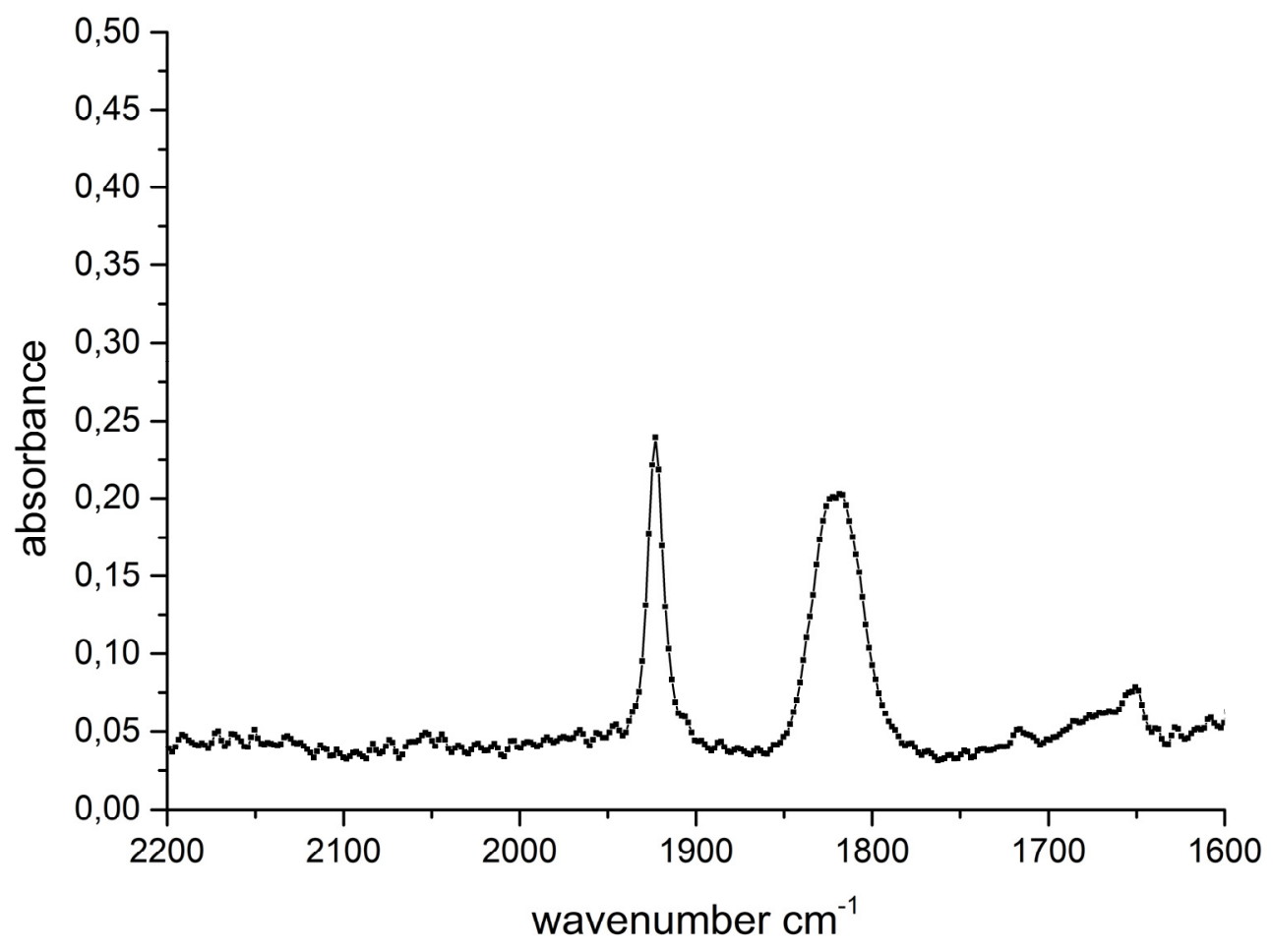

Figure S39. IR spectrum (dichloromethane) of complex 9.

Spectrum of complex 10

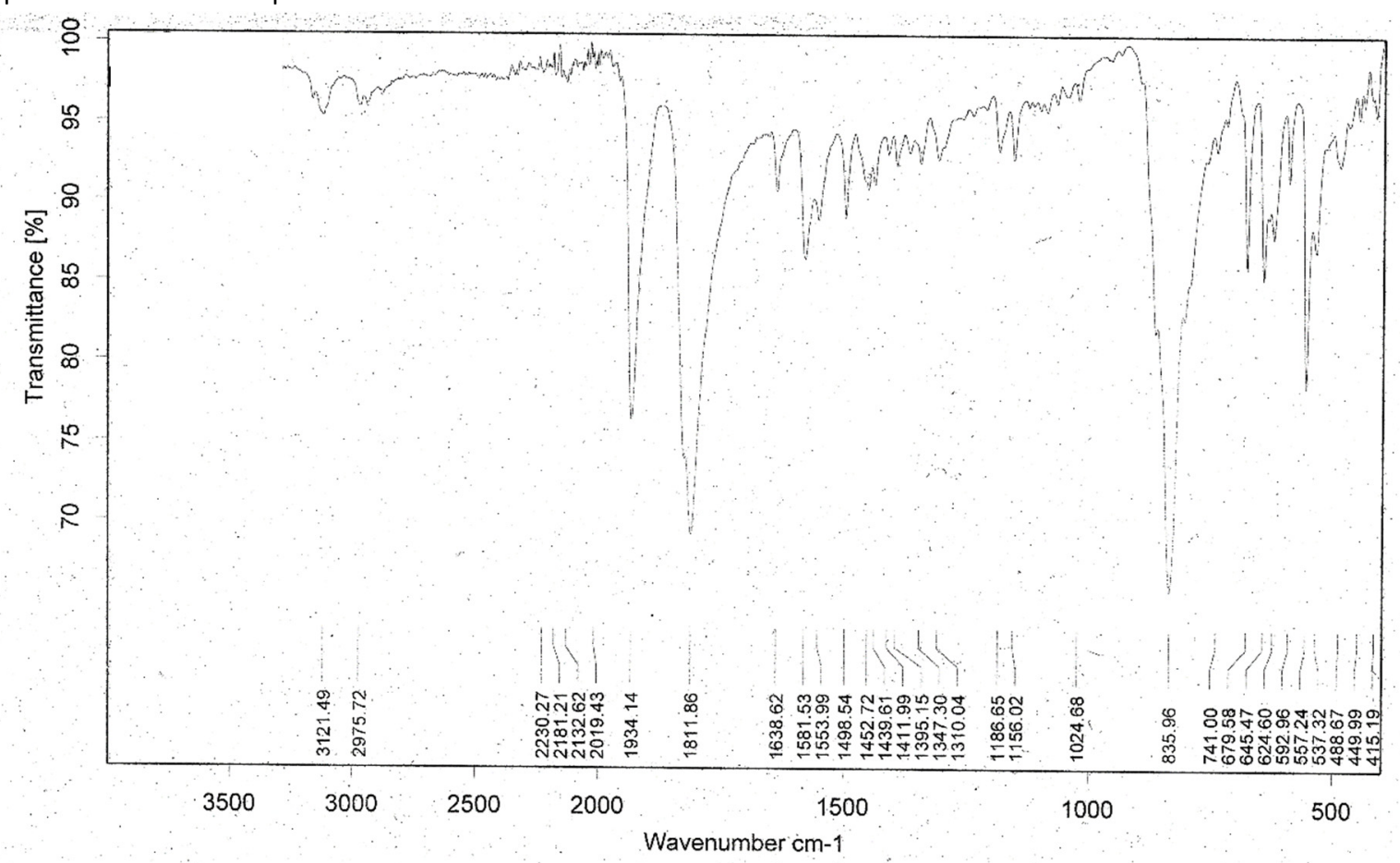

Figure S40. IR spectrum (ATR) of complex 10. 


\section{Additional X-ray structure analyses}

In addition to the X-ray structure analyses of new compounds presented and discussed in the manuscript, we provide here the molecular structures of the isostructural molybdenum and tungsten complexes, starting materials or side products. The general remarks referring to the X-ray structure analysis given in the experimental part of the manuscript apply here as well. Characteristic bond lengths and angles of the molybdenum and tungsten complexes are provided in the manuscript.

CCDC $2021894\left(\mathbf{1} \cdot \mathrm{HB}\left(\mathbf{C}_{6} \mathrm{~F}_{5}\right)_{4}\right), 2021895\left(2 \mathrm{BAr}_{4}\right), 2021898$ (5), 2021899 (6), 2021901 (8), and 2021902 (9) contain the supplementary crystallographic data for this paper. These data can be obtained free of charge via www.ccdc.cam.ac.uk/data_request/cif, or by emailing data request@ccdc.cam.ac.uk.

Molecular structure of complex 5

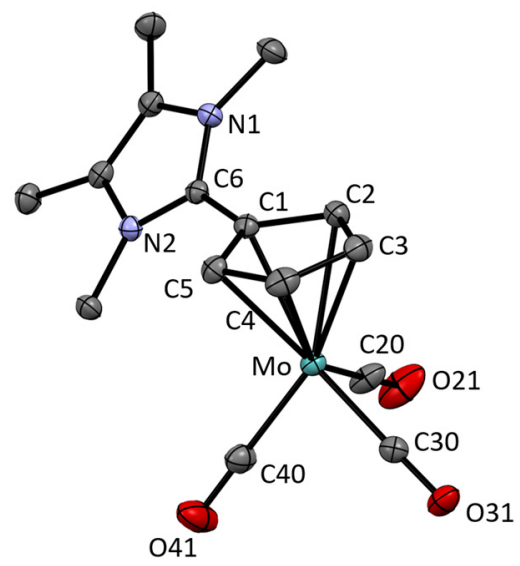

Figure S41. ORTEP-style plot of the molecular structure of complex $\mathbf{5}$ (anisotropic atomic displacement parameters at $50 \%$ probability). Hydrogen atoms are omitted for clarity.

Molecular structure of complex 6

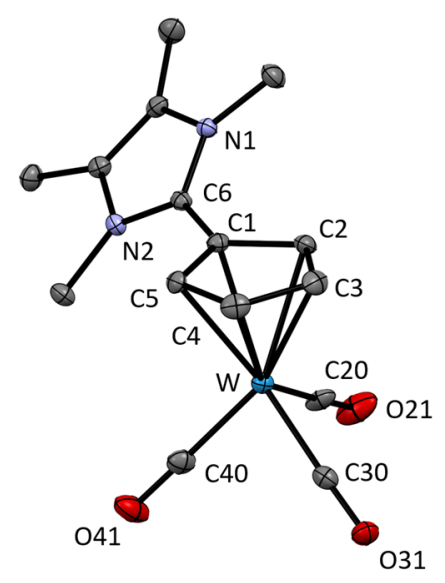

Figure S42. ORTEP-style plot of the molecular structure of complex 6 (anisotropic atomic displacement parameters at $50 \%$ probability). Hydrogen atoms are omitted for clarity. 
Molecular structure of complex 8

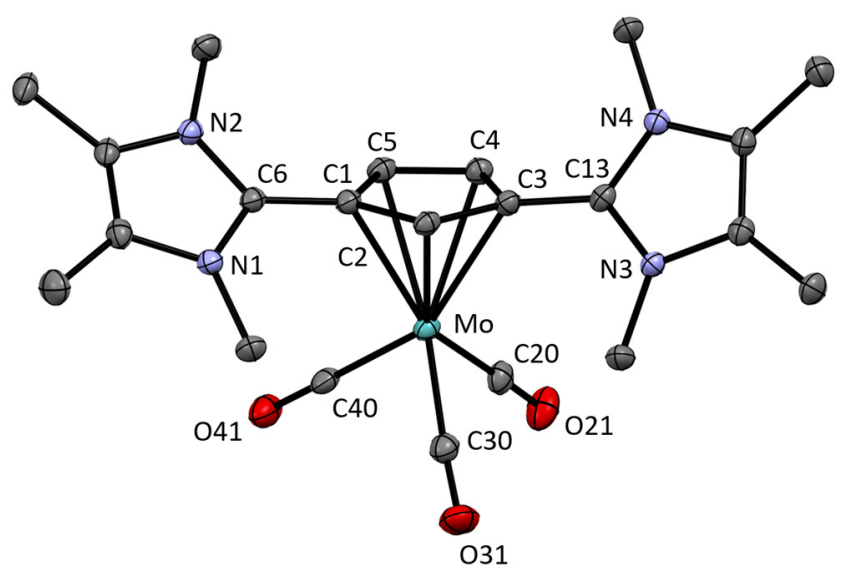

Figure S43. ORTEP-style plot of the molecular structure of complex 8 (anisotropic atomic displacement parameters at $50 \%$ probability). Hydrogen atoms and the $\mathrm{PF}_{6}{ }^{-}$anion are omitted for clarity.

Molecular structure of complex 9

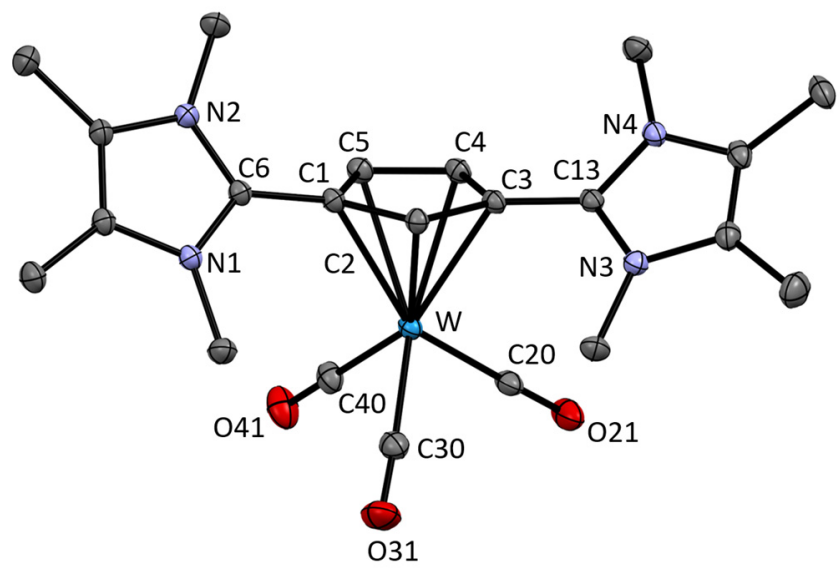

Figure S44. ORTEP-style plot of the molecular structure of complex 9 (anisotropic atomic displacement parameters at $50 \%$ probability). Hydrogen atoms and the $\mathrm{PF}_{6}{ }^{-}$anion are omitted for clarity. 
Molecular structure of the protonated compound $1 \cdot \mathrm{HB}\left(\mathrm{C}_{6} \mathrm{~F}_{5}\right)_{4}$

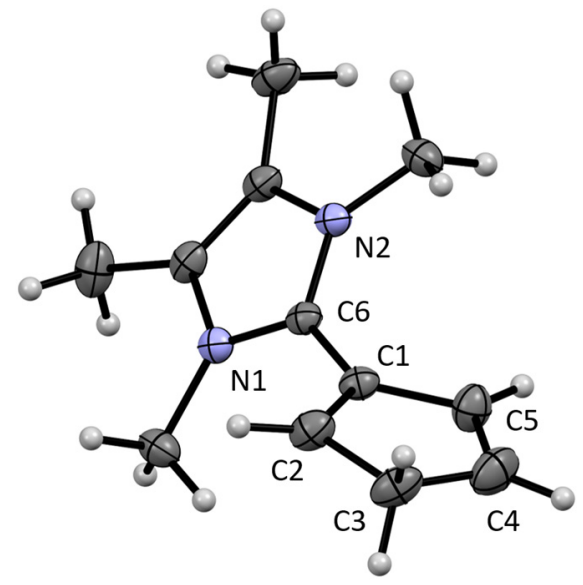

Figure S45. ORTEP-style plot of the molecular structure of the protonated compound 1 (anisotropic atomic displacement parameters at $50 \%$ probability). The $\left[\mathrm{B}\left(\mathrm{C}_{5} \mathrm{~F}_{6}\right)_{4}\right]^{-}$counterion is omitted for clarity. Selected bond length $[\AA ̊]$ and angle [ $\left.{ }^{\circ}\right]$ : C1-C6 1.453(2), N1-C6-N2 107.1(1), N1-C6-C1-C2 53.8.

Molecular structure of compound $2-\mathrm{BAr}_{4}$

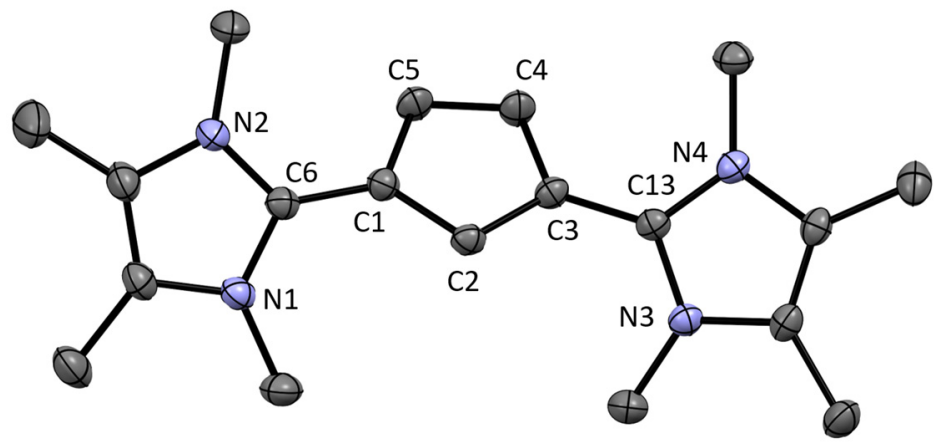

Figure S46. ORTEP-style plot of the molecular structure of compound $\mathbf{2}$ as $\mathrm{BAr}_{4}{ }_{4}^{-}$salt (anisotropic atomic displacement parameters at $50 \%$ probability). Hydrogen atoms and the $\mathrm{BAr}_{4}{ }_{4}$ anion are omitted for clarity. Selected bond lengths $[\AA \AA]$ and angles [ [ $]$ : C1-C6 1.436(2), C3-C13 1.439(2), C1-C2 1.406(2), C2-C3 1.406(2), C3-C4 1.426(2), C4-C5 1.383(2), C1-C5 1.424(2), N1-C6-N2 106.0(1), N3-C13N4 106.2(1), C2-C1-C5 107.9(1), C1-C2-C3 107.7(1), C2-C3-C4 108.1(1), C3-C4-C5 107.9(1), C1-C5-C4 108.4(1), N1-C6-C1-C2 38.7, N3-C13-C3-C2 40.5. 


\section{DFT}

The supplemental file XYZ-coordinates.Xyz contains the computed Cartesian coordinates of all of the molecules reported in this study. The file may be opened as a text file to read the coordinates, or opened directly by a molecular modeling program such as Mercury (version 3.3 or later, http://www.ccdc.cam.ac.uk/pages/Home.aspx) for visualization and analysis. 